\title{
Assessing Health Endowment, Access and Choice Determinants: Impact on Retired Europeans' (In)activity and Quality of Life
}

\author{
Luis Pina Rebelo $\cdot$ Nuno Sousa Pereira
}

Accepted: 16 December 2013/Published online: 12 January 2014

(C) Springer Science+Business Media Dordrecht 2014

\begin{abstract}
A future for the E.U., dominated by an ever-increasing population of retired citizens represents a major challenge to social and health policy in European countries. Under Rowe and Kahn's (Gerontol 37(4):433-440, 1997) perspective on positive aging, this paper is interested in exploring the role of health on citizens' active participation after retirement and social engagement to life and quality of life. This paper also aims at finding whether Sen's (Public health, ethics, and equity. Oxford University Press, Oxford, 2004) capability approach or cumulative disadvantage or advantage theory relative to the access to health also verifies in a context of multi-national developed economies. The first part of this study is therefore concerned with generating a health indicator that enables this, whilst controlling for individual heterogeneity in self-rated health responses from 10,859 retired individuals from the SHARE survey. Socioeconomic determinants of health are found not to be critical in determining health in such a developed context whilst cumulative advantage is found relevant for the positive aging of Europeans. Evidence is found that active engagement in activities and quality of life are most certainly a prerogative for the more educated and the healthier retirees, hinting a strategy for European policymakers: cumulative advantage, leveraged by education and health policy, might just be the long-
\end{abstract}

\footnotetext{
This paper uses data from the early release 1 of SHARE 2004. This release is preliminary and may contain errors that will be corrected in later releases. The SHARE data collection has been primarily funded by the European Commission through the 5th framework programme (project QLK6-CT-2001-00360 in the thematic programme Quality of Life). Additional funding came from the US National Institute on Ageing (U01 AG09740-13S2, P01 AG005842, P01 AG08291, P30 AG12815, Y1-AG-4553-01 and OGHA 04-064). Data collection in Austria (through the Austrian Science Foundation, FWF), Belgium (through the Belgian Science Policy Office) and Switzerland (through BBW/OFES/UFES) was nationally funded. The SHARE data set is introduced in Borsch-Supan et al. (2005); methodological details are contained in Borsch-Supan and Jurges (2005).
}

L. P. Rebelo $(\square)$

School of Economics and Management (FEG), Universidade Católica Portuguesa, Porto, Portugal e-mail: 1rebelo@porto.ucp.pt

N. S. Pereira

Faculty of Economics (FEP), Porto Business School and CEF.UP, University of Porto, Porto, Portugal e-mail: nsp@pbs.up.pt 
term strategy for contouring an aging and unproductive European population, transforming what could be a 'burden' into an asset.

Keywords Health policy strategies $\cdot$ Active aging $\cdot$ Well-being $\cdot$ Econometric modeling

\section{Introduction}

For the first time in most developed countries more people are dying than being born. Low fertility rates, and lower mortality rates resulting from high levels of expansion, rationalization and organization experienced by the health sector (Weisbrod 1991) have brought about one of the largest demographic challenges. An aging population is choosing early retirement from regular employment, with predictions for $60+$ year olds comprising up to one-third of the population in several countries in the next two decades (Siegrist et al. 2006). This predicts a future dominated by an ever-increasing population of retired citizens, without enough younger workers to fund (via taxes or social contributions) retirement programs or other state welfare agendas, representing a major challenge to social and health policy in European countries. However, to what extent does this population represent a burden, or can it be an active asset to the economy and society? Under the latter perspective the question which should be raised by policymakers is how (in)active is in fact this population, and what exactly determines its (in)activity. Health has been proposed as one of its main determinants (see recently, for instance, Siegrist et al. 2006), and the evaluation of this proposition and the dimension of this phenomenon is part of what constitutes the subject of interest of this paper. A further step is given with the estimation of how each of the health determinants may act upon the activity of retirees. Nonetheless, in the matter of assessing the welfare state, policymakers should not only be concerned about the distribution of resources and health, but also with the general well-being of an ever-growing 'third age' population. Thus, the aim of this paper is twofold.

The first part of the paper particularly concerns whether access to health is constrained by socioeconomic characteristics and whether Sen's (2004) capability approach or Cumulative Disadvantage or Advantage Theory (Dannefer 2003) verifies in health outcomes, in a context of multi-national developed economies, comparing with developing countries. A second part of the paper is devoted to positive aging in developed economies [particularly under Rowe and Kahn's perspective (1997)], and finding how health co-exists with other determinants of active participation and social engagement to life and determines quality of life, and consequent policy implications.

\subsection{Health and Well-Being in Different Developmental Contexts}

The findings in health economic literature suggest that economic stability is essential for the well-being of the elderly that have lived their youth in a developing country, through insecure economic times, experiencing poverty and instability (Hsu 2010). However, in developing economies, the relationship between economic status and subjective well-being has been found weaker in high-income economies (Howell and Howell 2008). In Taiwan, for instance, physical disabilities were found relatively insignificant, as were early year factors, such as education to explain current life satisfaction, possibly due to this 
population valuing more the relative stability of recent years which contrasts to adverse conditions in an earlier age, where only the fittest survived (Hsu 2010). In turn, psychological health has been found to be much more related to subjective well-being (Hsu 2009). Contrastingly, studies in developed countries have found both physical conditions and socioeconomic status to be related to life satisfaction, but the later only in elderly men, not women (Berg et al. 2006), with successful aging definitely involving not only individuals' physical health and psychological well-being, but also social support and engagement in productive activities (Rowe and Kahn 1997). In sum, different socioeconomic realities may play different roles in determining health (and health self-perception), and both might produce very different results in older citizens' well-being, depending on the cultural or developmental context. Thus, the aim of this paper is twofold.

\subsubsection{Health and Its Determinants in Different Socioeconomic Contexts}

First the goal is to generate a complete and accurate measure for health to evaluate what are the determinants of health in a multi-cultural European developed context. Sen (2004) argues that health is a complex matter with many dimensions, and as such cannot be measured based solely on the mere status, but should also take into account the access to opportunities. Cumulative advantages and disadvantages theory has explained how early advantages or disadvantages, such as a lower educational base, or other forms of inequality could shape the exposure to risk or opportunity, and thus reveal its effects on health in old age (Dannefer 2003; Ferraro and Shippee (2009)). However, the question is whether these access advantages or disadvantages are present in developed economies, with reduced inequalities and widespread coverage (whether private or public) in the access to care.

Additionally, accessing health is a challenging task, particularly across a large population in a multi-cultural context. Self-reported health is the most widely used measure as part of social statistics, however comparisons across diverse socio-economic or cultural groups have proved in certain cases to entirely mislead public policy on health care and medical strategy. This is because an individual's access to the proper means, knowledge and social experience may not only restrict his or her access to health, but may also seriously limited his or hers internal assessment. Sen (2002) famously quoted evidence from India, where Kerala, the state with the highest life expectancy and levels of literacy (thus possibly with greatest awareness) consistently shows the highest rates of self-reported morbidity.

We therefore build on Jurges (2007) to create an indicator that cross-references objective with subjective self-reported measures of health, but extend it to include influences of other nature. It is inspired by Sen's well-known distinction between achievement and the capability of achieving, in this case, good health, raising a question of social justice in health: "the factors that can contribute to health achievements and failures go well beyond health care, and include many influences of many different kinds, varying from genetical propensities, individual income, food habits, and lifestyles, on the one hand, to the epidemiological environment and work condition, on the other." (Sen 2004). We are interested in finding whether this hypothesis verifies in an economic developed context, particularly with respect to the capability or access factors, which are consistent with cumulative disadvantage or advantage theory. Or whether, contrary to developing countries where access to health may be conditioned by socioeconomic status, and possibly only the fittest have survived into an older age (Hsu 2010), in developed economies these effects are marginal, and physical disabilities or psychological dimensions of well-being (Rowe and 
Kahn 1997) are more determinant in explaining health outcomes amongst a population unaccustomed to adverse conditions.

\subsubsection{The Role of Health in Active Participation and Well-being}

In the context of developed countries, positive aging literature has regarded successful aging as multidimensional, involving not only individuals' physical health, cognitive and psychological well-being, but also active engagement with life (Rowe and Kahn 1997). The second goal is thus to evaluate the impact that physical and psychological health determinants may have in the active engagement of older European retired citizens above 50 and their quality of life, and thus what is the role played by this dimension of the positive aging hypothesis. This dimension will also be compared with other strands of literature that believe demographics (e.g. age and gender) or socioeconomic influences are determinant in elderly well-being. Though this is fairly consensual in the case of developing countries, with plentiful evidence (Hsu 2010; Chou and Chi 2002; Li et al. 2007), only some is found for developed countries (Berg et al. 2006; Borg et al. 2006), with most of the evidence pointing to weaker socioeconomic status influences on high-income countries (Howell and Howell 2008) or simply relative or comparative status influence (Ball and Chernova 2008; Easterlin and Plagnol 2008).

The measure for well-being used is quality of life in early old age, that was measured by using the CASP-12 (Knesbeck et al. 2005), intended to identify and quantify those aspects of quality of life in early old age that are specific to a stage in the life course characterized by transition from work to retirement, by an increase of personal freedom and by new options of social participation. Quality of life is therefore regarded as the degree to which human needs are satisfied, which in this stage of the life course translates itself into four domains of need which are particularly relevant: control, autonomy, self-realization, and pleasure (Patrick et al. 1993; Turner 1995; Doyal and Gough 1991).

Section 2 presents our model and conceptual framework to assess health status and each of its determinants, and the first set of results obtained in the process of generating a comparable health indicator for individuals with health reporting heterogeneity. Section 3 proceeds with analyzing the effects of health, and other determinants of participation rates and quality of life of elder Europeans, and finally Sect. 4 presents our concluding remarks.

\section{Method}

\subsection{Creating a Comparable Health Index Whilst Accounting for Heterogeneity in Reporting Behavior}

In health economics literature, there is a conceptual contrast between "internal" views of health (based on the patient's own perceptions) and "external" views (based on the observations of doctors or pathologists) (Sen 2002). Major tension often exists between evaluations based respectively on the two perspectives. A mere sum of objective measures is limited to the extent of not assessing the gravity of each unique condition, and the different impacts it might have over individuals with different socio-economic backgrounds or lifestyle choices. Self-assessed general health measures, most commonly used, are subjective, and may come biased by heterogeneity of perspectives or personality, which reflect different reference levels against which individuals possibly in the same state of health judge their health and categorize it in an ordinal response. Their comparability 
across groups of individuals, with different norms and expectations, has been questioned in a number of studies (Kerkhofs and Lindeboom 1995; Groot 2000; Sen 2002; Lindeboom and Van Doorslaer 2004; Jurges 2007). For instance, a common finding is that older respondents tend to have a 'milder' view of their health, i.e. they tend to rate their health as better than otherwise comparable younger respondents (Groot 2000; Van Doorslaer and Gerdtham 2003).

One of the purposes of this study is thus to compute a continuous health indicator or index, that enables us to go beyond the mere testing and recognition of the existence of reporting heterogeneity across different (age, educational, income, linguistic, cultural) groups (as did Lindeboom and van Doorslaer 2004), and actually quantify the effects of these capabilities, whilst also adjusting for an individual's internal references, self-perception and cognitive bias. Following Jurges (2007), the basic assumption is that in self-reporting health (SRH) status, there is an underlying health level for each individual which could be measured by a comparable, continuous, latent (i.e. unobservable) health indicator. These comparable health levels may be found by expunging the reporting scale on self-perceived health from reporting differences resulting from personality traits (pessimism, optimism, etc.), cultural or linguistic and educational heterogeneity and cognitive functioning; thus leaving only the objective effects on health, of various natures: chronic disabilities and physical limitations, behavioral risks resulting from lifestyle choices and socio-economic 'abilities' to 'access' health.

Following Rebelo and Pereira (2011) and Jurges (2007), a discrete choice index model is proposed, with self-perceived health as the dependent variable with five ordinal outcomes, ranging from poor to excellent. It is based on the assumption that when respondents answer survey questions about their health, they assess their own health $\left(\mathrm{H}^{*}\right)$, a latent continuous variable (possibly captured with a measurement error \& (Crossley and Kennedy 2002)), and project this value onto the ordinal scale provided (H). However, the criteria each individual uses when dividing this real line into segments (by cutting-points $(\mu)$ which define these categories) will depend on individual heterogeneous perceptions. The purposed model is as follows:

$$
\begin{aligned}
& H *=\alpha+\beta^{D \prime} D+\beta^{Q \prime} Q+\varepsilon \\
& H= \begin{cases}0, & \text { if } H * \leq \mu_{0} \\
1, & \text { if } \mu_{0}<H * \leq \mu_{1} \\
2, & \text { if } \mu_{1}<H * \leq \mu_{2} \\
3, & \text { if } \mu_{2}<H * \leq \mu_{3} \\
4, & \text { if } \mu_{3}<H *<\mu_{4}\end{cases}
\end{aligned}
$$

where,

$$
(\varepsilon \mid D, Q) \sim N(0,1)
$$

and the cutting-points are given by:

$$
\begin{aligned}
& \mu_{0}=0 \\
& \mu_{j}=\mu_{j-1}+\exp \left(\lambda_{j}+\gamma_{j}^{\prime} D+\theta_{j}^{\prime} S P\right), \quad \text { for } j=1,2,3 \\
& \mu_{4}=+\infty
\end{aligned}
$$

The control for heterogeneity in response and subsequent readjustment of each individual's reporting scale, can thus be made by letting the cutting-points (or thresholds each 
individuals use as an internal reference to classify their SRH in a discrete scale) vary according to the combination of their cultural or linguistic background, personality traits, cognitive abilities, education, and so forth, whilst afterwards reclassifying them.

The latent variable for health $\left(\mathrm{H}^{*}\right)$ is regressed against two vectors which include covariates which solely influence health per se $(\boldsymbol{Q})$ and influences which simultaneously act upon health and self-perception $(\boldsymbol{D})$. As in Jurges (2007), quasi-objective ${ }^{1}$ physical or chronic $(P h \subset Q)$ and mental conditions $(M h)$ are considered, though unlike him the later are considered to possibly influence health and reporting behavior $(M h \subset D)$. This latent variable $\left(\mathrm{H}^{*}\right)$ will serve for the creation of a 0-to-1 health index, a 'proxy' for the real health status, where 0 represents the worst observed health state ('near death') and 1 represents 'perfect health'. The presence of a condition reduces the health index by some given amount or percentage, a disability weight (Jurges 2007). These will be equal to estimated coefficients divided by the difference between the highest and lowest predicted health level (corresponding to 'near death' and 'perfect health', respectively). However, as previously mentioned, health is a complex matter which may not be simply described by the mere presence of physical conditions. These can be attenuated (or potentiated) by access (or lack of it) to health facilities (Sen 2002, 2004), according to individuals' characteristics as to exposure to certain country $(C \subset D)$ health systems, socio-economic or educational backgrounds ( $S e \subset D$ ). Thus, Jurges analysis is further extended to include this type of information, as well as other dimensions of health which are directly influenced by lifestyle choices, as to behavioral risks $(B h \subset Q)$ undertaken by each individual (e.g. alcohol drinker, smoker). This addresses one of the limitations associated to most objective measures (mere sum of conditions), which are usually limited to the extent of not assessing the gravity of each unique disability, and the different impacts it might have over individuals with different socio-economic backgrounds or lifestyle habits.

As to influences on thresholds, i.e., over individual self-perception, socio-economic, cultural and linguistic differences are also allowed to act upon self-perceptions, besides on health per se, being considered in a common vector $(S e, C \subset D)$, as previously specified. They were chosen based on the works of Dewey et al. (2005), and the SHARE database used to create a number of measures on mental health $(M h \subset D)$, personality traits such as pessimism, and cognitive functioning $(S P)$.

This represents an advance in dealing with group heterogeneity in reporting behavior, which researchers have long attempted to. King et al. (2004) have proposed the use of vignettes to rescale individual threshold criteria, by comparison to how they perceive fictitious individuals' (with certain attributes) health status. However they do not deal directly with cultural nor socio-economic differences, which is a crucial aspect of our European reality. Others deal with the latter, ignoring the former. Kerkhofs and Lindeboom (1995), van Doorslaer and Jones (2003) and Lindeboom and van Doorslaer (2004) follow diverse empirical strategies which have in common the estimation of separate ordered response models for sub-groups in their sample stratified according to age, sex, education, income and language. They present a framework for individual reporting behavior that merely enables them to formally test, via straightforward likelihood ratio tests (comparing the sum of likelihood values for two sub-groups with the sum of the likelihood for total group), whether variations in responses to health questions reflect true health differences or reporting behavior. However, by doing this estimation procedure over sub-groups of their sample, they lose the ability to actually estimate and quantify two important effects: the

${ }^{1}$ Quasi-objective because we base ourselves in self-reports of disabilities objectively diagnosed by physicians. 
actual effect of the stratifying variables (socio-economic characteristics, e.g., income) on health per se; and their effect (e.g. high versus low income) on self-perception.

The proposed methodology solves for these problems. Through HOPIT estimation (Greene and Hensher 2010) we will obtain a vector of estimates for the effects on the health index, $\beta^{\mathrm{D}}$ (separate estimates for variables common to the health index and threshold), for the other disability with sole effects on health index $\beta^{\mathrm{Q}}$, and for reportingstyle effects, i.e., on thresholds- $\gamma_{j}$ and $\theta_{j}$.

This represents an improvement on Jurges (2007) in finding a more complete and more accurate health measure in three ways: (1) The methodology proposed in Rebelo and Pereira (2011), following Greene and Hensher's (2010) HOPIT, is used. It was reported to have a $43.5 \%$ higher out-of-sample predictive power than Jurges' (2007). An additional advantage of it is that it allows a separate identification of the influences associated to covariates that act simultaneously upon health and the self-perception mechanism implicit in every individual's self-categorization; (2) The study goes beyond the mere dimension of health pathologies with which each individual is endowed, by considering access and behavioral determinants for health; (3) After Rebelo and Pereira (2011) found that Jurges' (2007) reported cultural and linguistic differences, represented by country dummies, really didn't explain most of the self-assessment of health process, the authors will further explore what other factors might in fact do.

\subsection{Identification Problem and Empirical Strategy}

The described method could raise some identification concerns because its goal is to control for and estimate the effects on health of socio-economic variables such as income and education. However, these variables are likely to be influenced by health themselves. The issue of circularity is solved for because we are solely interested in the retired population. Since one can hardly argue that for this population, health status may influence either their future educational achievements or their generating income ability (which is now a pension), the direction of the causality relationship with health seems unquestioned.

\subsection{Data and Variable Description}

Data was from the second release of the first wave of the Survey of Health, Ageing and Retirement in Europe (SHARE) collected in 2004 was used. SHARE is a multidisciplinary, cross-national micro data base, containing information on health and socioeconomic status for around 22,000 Continental Europeans aged above 50. However, the scope of this study is restricted to the retired proportion of the sample aged above 50, which amounted to 11,419 individuals, from ten European countries-Austria, Denmark, France, Germany, Greece, Italy, the Netherlands, Spain, Sweden and Switzerland. One of the merits of this database is that it relies in consistent sampling frames and survey design across all participating countries, resulting in a high degree cross-national comparability. It includes imputations ${ }^{2}$ for some missing economic data based on extensive research (Brugiavani et al. 2005; Christelis et al. 2005). After accounting for economic missing data, some missing data was registered particularly for psycho-cognitive variables. However, only complete responses were considered, given that when the loss of cases due to pair-wise deletion is small, and less than about

\footnotetext{
${ }^{2}$ Imputations on amount variables were conducted using the unfolding brackets and the conditional hotdeck method. Imputations on frequency variables were conducted using regression methods. Imputation minimizes bias, and uses 'expensive to collect' data, that would otherwise be discarded.
} 
$5 \%$, biases and loss of power are inconsequential, particularly in cross-sectional studies (Graham 2009). This merely reduced the sample in $4.9 \%$ to a total of 10,859 individuals.

The dependent variable is a self-perceived health measure with 5 ordinal outcomes, ranging from 'poor' to 'excellent', following the usual self-rated health (SRH) US scale. ${ }^{3}$ Figure 1 shows the age-sex standardized distributions of self-reported general health across the 10 considered countries, i.e., the health distribution across the 5-point ordinal scale if each country had the same age and sex distribution of individuals, but only for the retired individuals. As reported by Jurges (2007), we observe that the distribution of health levels, according to self-reports, presents strong differentials across Europe, which seems inconsistent with other well-known indicators such as life-expectancy at birth (see Human Mortality Database 2002). The highest proportion of retired respondents that classify themselves as healthy live in Northern European Countries such as Denmark and Sweden, while the lowest live mainly in Mediterranean Countries such as Italy and Spain, though Germany is the country with the poorest results. A first goal is to determine the more complete and accurate underlying state of health than Jurges (2007), and whether these conclusions remain after accounting for self-perception bias and reporting heterogeneity.

As independent variables, endowment determinants of health are considered such as self reported diagnosed chronic conditions, functional limitations, activities of daily living (ADL) limitations, physical measurements (hand grip strength and gait speed) and mental health indicators (we use the Euro-D scale for depression). Behavioral risk indicators are also considered, which result from voluntary choices such as smoking behavior, nutrition, alcohol abuse, and physical inactivity and finally socio-economic dimensions such as income, wealth and educational attainment, which act in the sense of enabling (or limiting) access to health care and prevention.

Finally, variables included in the vector of influences over the thresholds ( $\boldsymbol{D}$ and $\boldsymbol{S P}$ ) were country dummies to account for linguistic and cultural bias in self-rating behavior (Jurges 2007) but also a number of cognitive and psychological individual characteristics, and socioeconomic variables, per se, to control for individual socio-economic stratifyers which might influence individual ability to correctly perceive and evaluate health status. Appendix 1 presents a more thorough description of all variables used and details on their construction.

Total and average country incidence for conditions and other covariates are reported in Table 1. Retired respondents are around 70 years old, with Switzerland having the eldest, and Austria and Italy the youngest, in average. Contrary to overall SHARE sample respondents, in which there is a majority (54.5\%) of female respondents (Jurges 2007), the retired sample has a majority of male respondents (54.2\%), with the percentage of women varying significantly across countries, Spain having the most extreme disproportion ( $26.2 \%$ female respondents). Health distributions will be compared in the following section after age-sex standardization.

Disability incidences somewhat vary across countries, with arthritis having the highest range between countries. However the largest disparities are found for behavioral factors, such as percentage of former smokers (in the Netherlands versus Austria) and drinking behavior (Italy versus Sweden), all of which Jurges didn't consider. However, the highest inequalities are found when considering access variables namely education and income with the highest differences in low and high education dummies in Spain and Italy

\footnotetext{
3 Jürges et al. (2007) showed that there are non-significant differences between the US and the E.U. scale (ranging from 'very poor' to 'very good'). The two scales presented similar correlations with demographics and health indicators, and a very similar pattern of variation across countries. The authors did not find evidence that the EU version is preferable to the US version as standard measure of SRH in European countries. We ended up opting for the US scale because it exhibited a greater symmetry in responses across the 5 categories.
} 


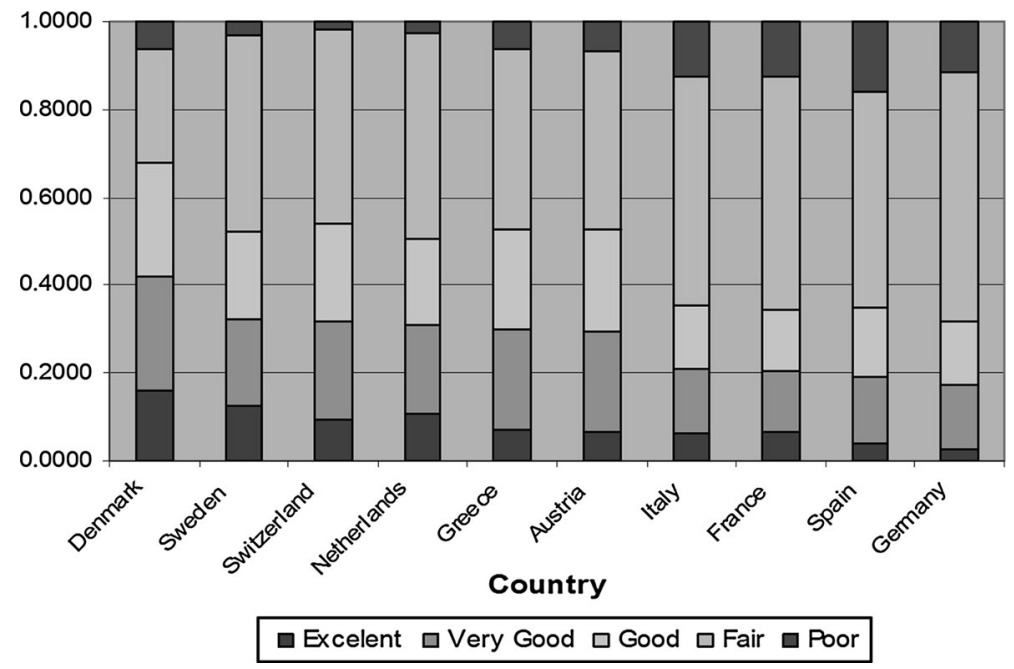

Fig. 1 Age-Sex Standardized Self-reported General Health, by country for the 10,859 retired individuals

contrasting with larger apparent equality in Germany, for the retired sample. Sweden registered the largest proportion of high income citizens and the lowest proportion of low income citizens whilst the larger income inequality is found in Spain and Greece.

\subsection{A First Set of Results. Health Endowment, Access and Choices}

A first estimation procedure according to the conceptual framework presented was conducted to the sample of 10,859 retired individuals, and the results are in Table 2. The fourth column shows the implied disability weights used in the rest of the paper. They are computed as the regression parameters from the HOPIT model divided by the range of its linear prediction. Amongst the highest disability weights are Parkinson's disease, stroke, heart attack, and chronic lung disease, as in Jurges (2007). However, comparing with them, after self-perception bias is accounted for, cancer and malignant tumor has leaped to a fourth position, which seems only reasonable. As to all other common disability weights on the latent health index, they have generally decreased in proportion, which is only natural since we are considering a wider combination of possible influences. Interestingly, behavioral risks seem to have a relatively strong and significant impact on the state of health, not only the previously considered nutritional behavior indicators (bmi) but also choices related to smoking behavior $(1.13 \%)$ or particularly the practice of sports or physical activities $(6.22 \%)$ and mobility $(10.70 \%)$.

As previously found (Rebelo and Pereira 2011) country disability effects proved to be all largely insignificant, suggesting that disabilities should have the same average weight in all countries. ${ }^{4}$ However, the hypothesis that socio-economic determinants of the access to

\footnotetext{
${ }^{4}$ The estimation procedure was repeated using separate country samples. However given the large loss of sample size, results were largely insignificant. We estimated simplified versions of our model for each country (reducing it to Jurges (2007) basic model, with physical disabilities, dropping most of the significant covariates on the threshold equations), having included age and gender controls given the different country proportions. Still, even though results for the most common disabilities were similar across countries, the authors have very little confidence in the generated results. Small samples rendered low-incidence disabilities (e.g. Parkinson) largely insignificant in explaining SRH, which is fairly absurd and incoherent with the total sample results.
} 


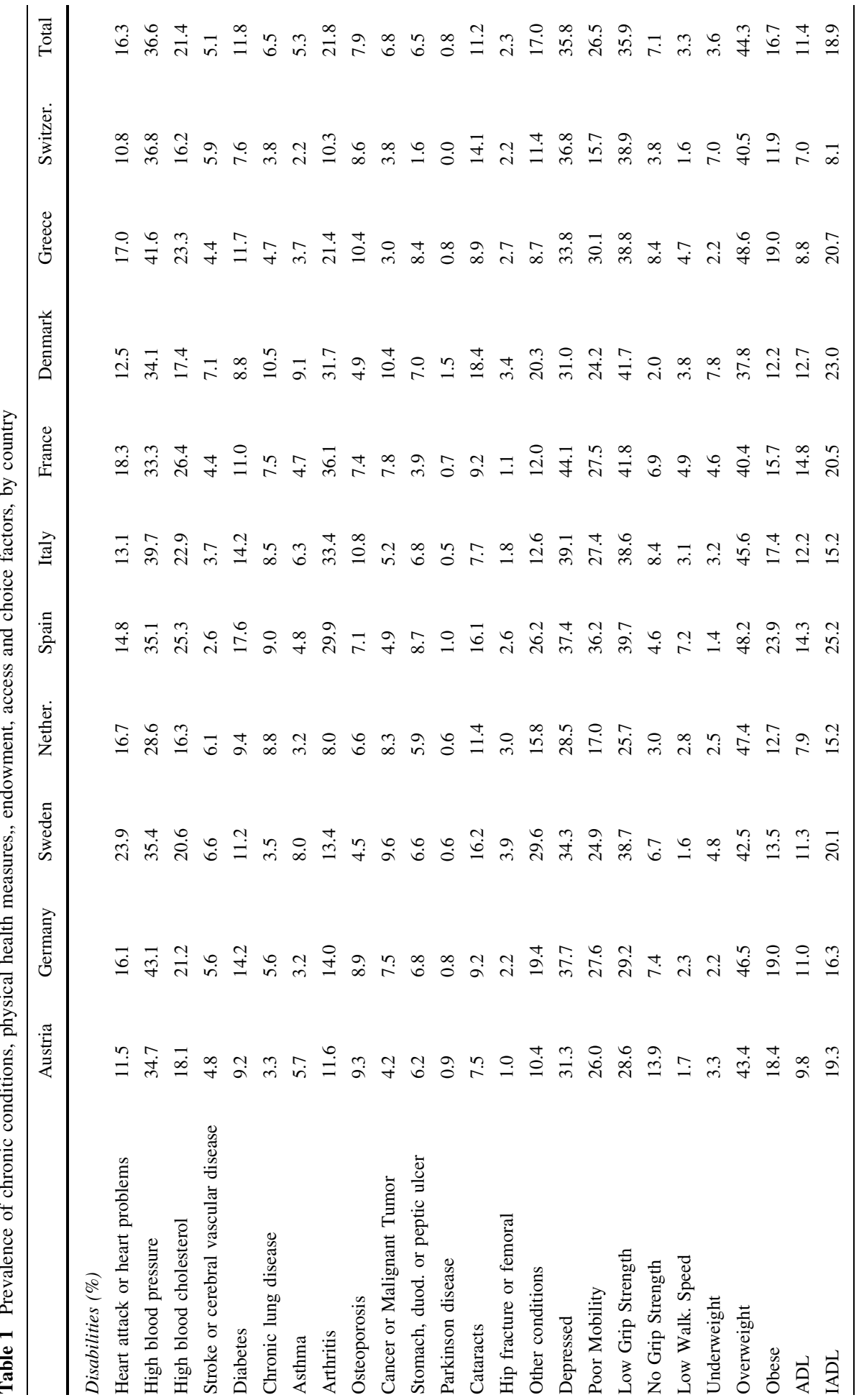




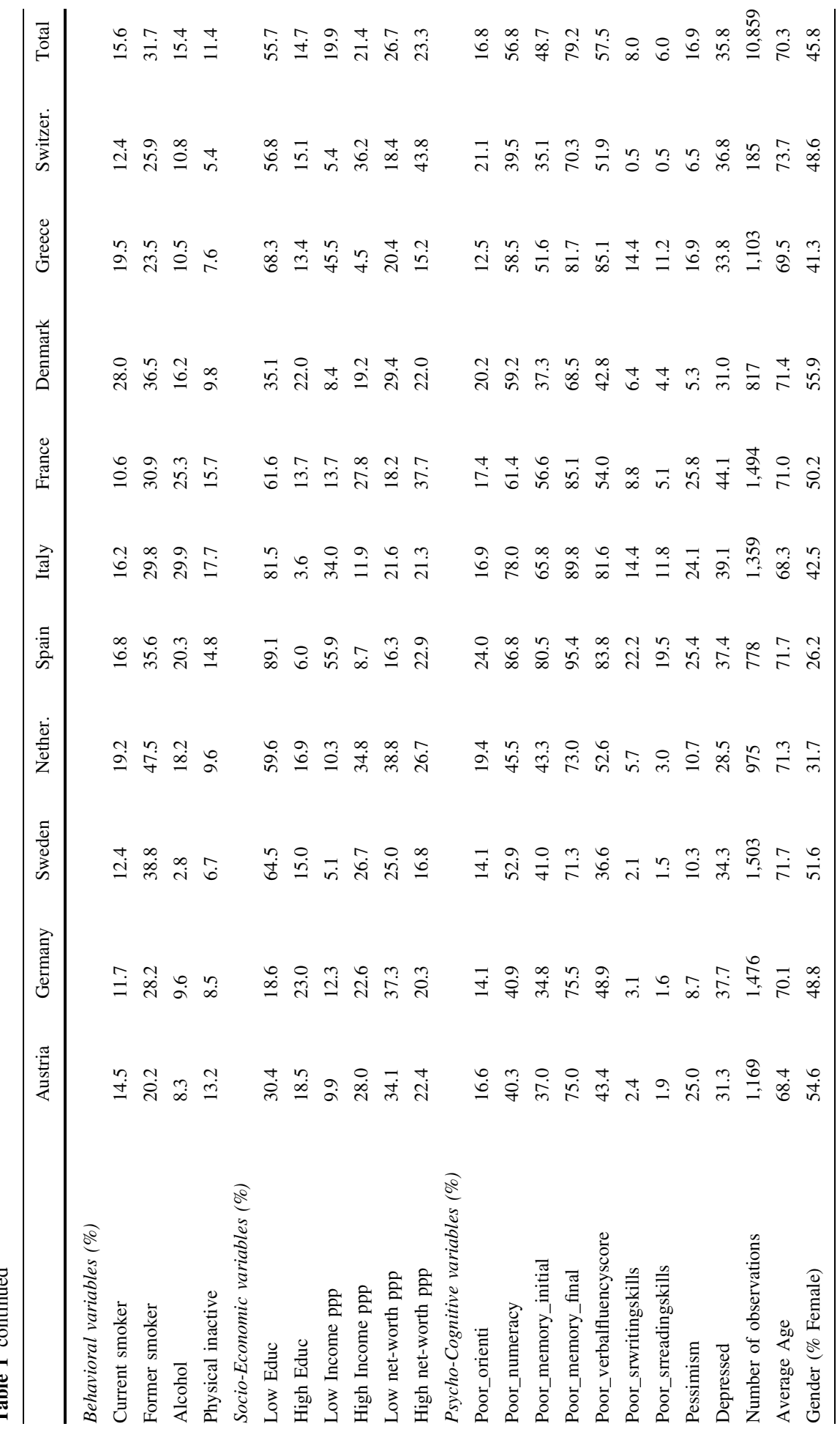




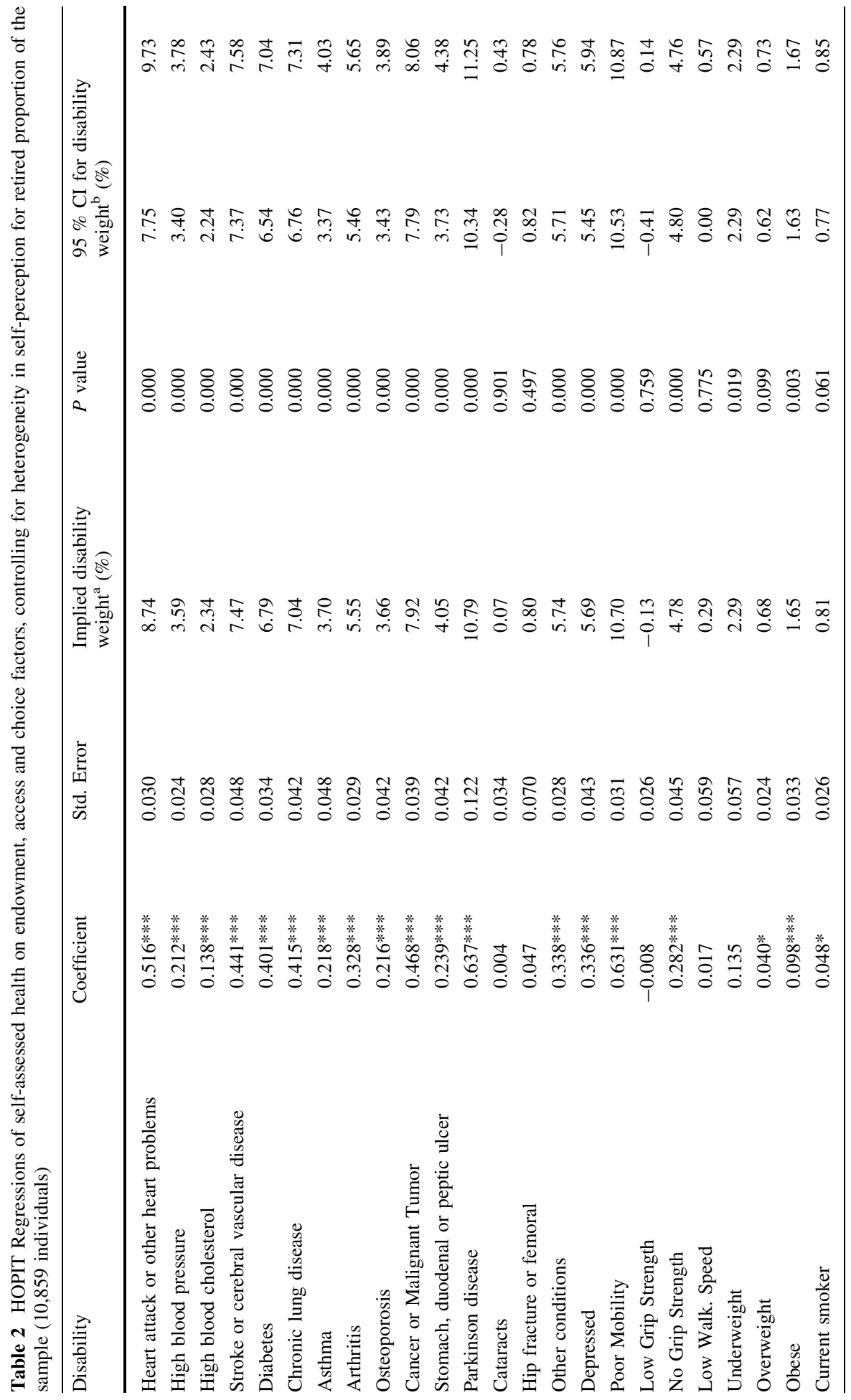




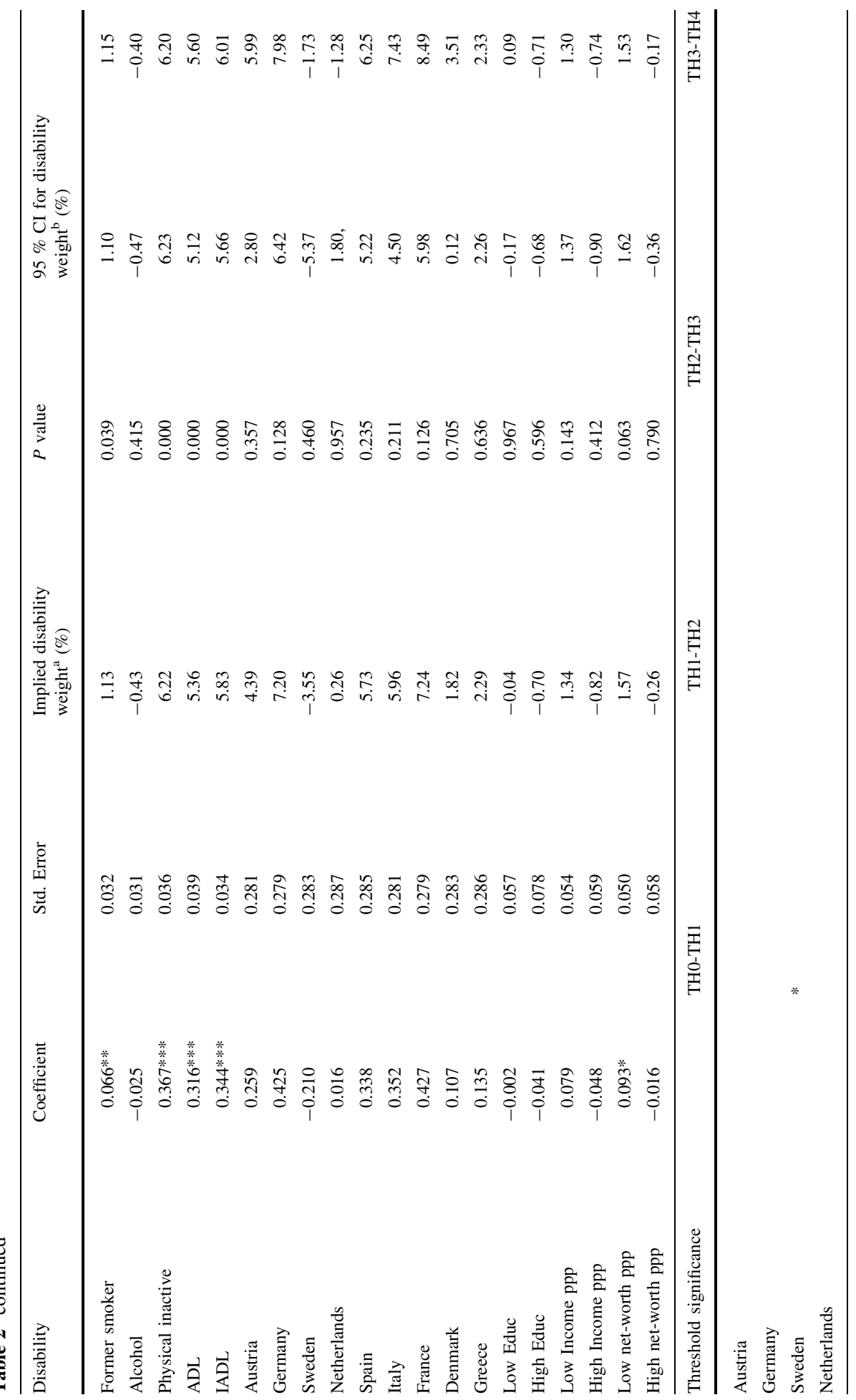




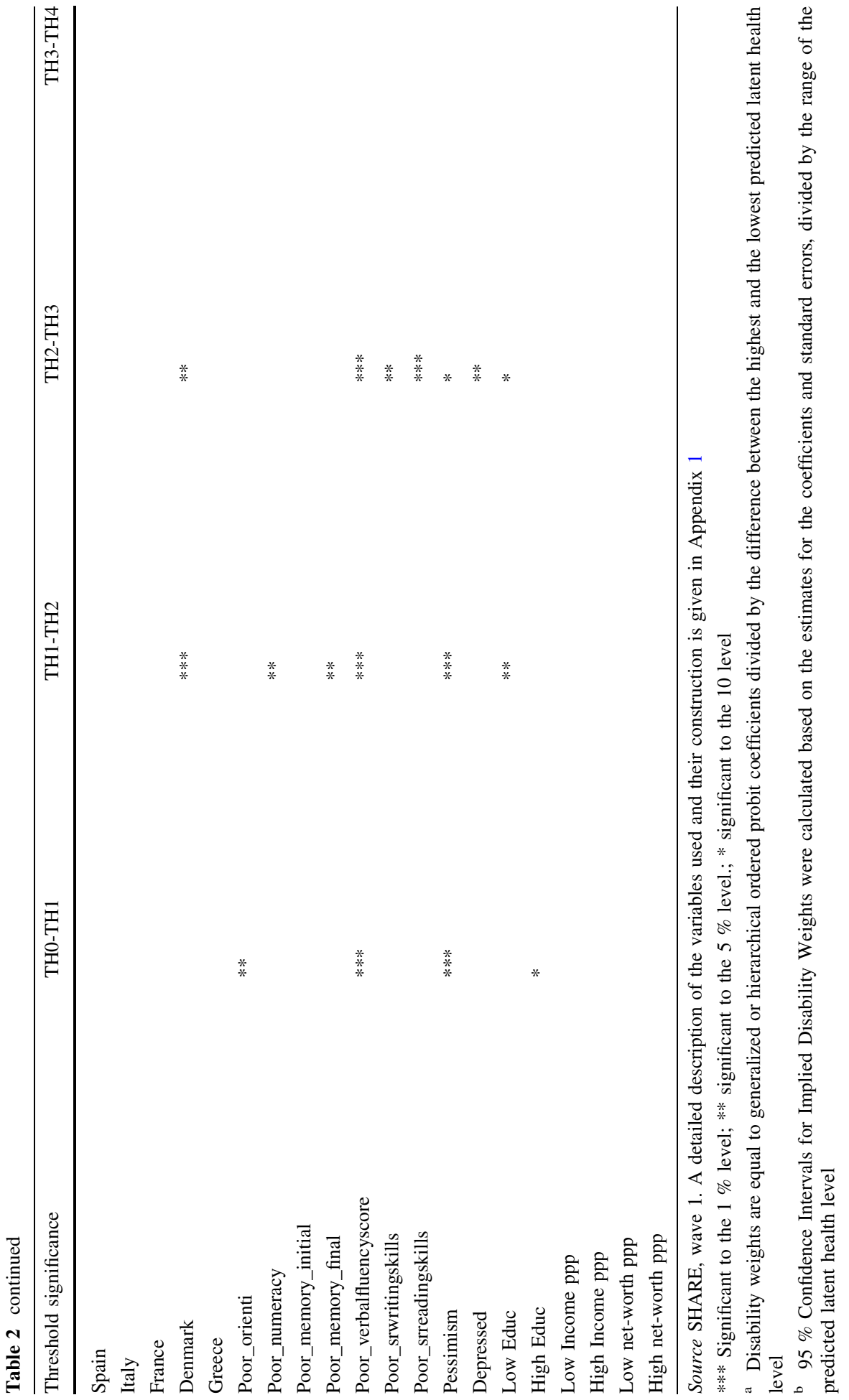


health care, from the different effects referred by Sen (2004), are also found to be mostly insignificant in older age. Education, usually acquired in an earlier age, is found to be insignificant, which proves against the theory that cumulative advantages or disadvantages could impact health in a later stage, (Dannefer 2003). This corroborates what was previously hypothesized: physical disabilities or psychological dimensions of well-being (Rowe and Kahn 1997) are more determinant in explaining health outcomes for developed economies, amongst a population unaccustomed to adverse conditions. This may also be explained by the fact that in such a developed country, European context access to health and the health care system for the retired is somewhat guaranteed. The finding that socioeconomic status has no particular relevance in determining the health of older Europeans will be critical to the methodology chosen in Sect. 3, as it rules out and possible circularity between those variables, before proceeding with analyzing impacts physical and psychological health may have upon other activity dimensions of elderly European in Sect. 3.

This model identifies the significant influences on the self-categorization process of the average SHARE respondent when assessing his or her own health, and thus revealing a comparable population's latent health status. Contrary to Jurges (2007), it is not with linguistic or cultural differences that one should be concerned when trying to disintricate the true state of public health from the self-revealed state (Rebelo and Pereira 2011), across a diverse European reality (with the exception of Denmark), but rather with factors which might influence self-awareness and perception, particularly within an older population. Cognitive measures are found to have a strong significant influence on the self-categorization process, namely verbal fluency. Furthermore, pessimism, a personality trait which reveals how people cope with potentially stressful situations (Aspinwall and Taylor 1992), is found to play a very significant role in explaining how people use different standards when revealing and projecting their state of health on a qualitative ordinal scale. It is particularly influent in explaining the lower health thresholds, i.e., a stressful situation, which is only natural. Accounting for these perception differences will most certainly produce a very different and more realistic health distribution across our sampled Europeans.

The methodological modification (after Greene and Hensher 2010), now allows a regressor to simultaneously act upon threshold and index values and be separately identified (even if found to be insignificant in some cases). However insignificant as determinants of health per se, the hypothesis that some socio-economic characteristics such as education (Sen 2002) have an active influence in the way individuals reveal their state of health, is corroborated by the results, given the significance of education in threshold levels.

After estimating each of these individual endowment, access and choice contributions on health, a continuous health index measure was computed for each individual according to his or her characteristics, subtracting each average disability weight from the 'best health' value of 1 . Since these average disabilities have been computed for an average individual from this sample, controlling for the diversity in response, the health index will now come free of any socio-economic, cultural or psycho-cognitive self-perception bias, and thus comparable across all individuals in the sample. This continuous measure for health, varying in the $0-1$ interval, will prove extremely useful in analyzing the impact on retired individuals' (in)activity later on.

In order to compare the aggregate distribution in each country (which results from a sum of every individual citizen's corrected health status) with the self-revealed one of the SHARE questionnaire (in Fig. 1), a re-classification was done. The original aggregate health distribution of the entire sample (irrespective of country or socio-economic origin) 
was taken as a reference. The value of the health index corresponding to the quantile level of each ordinal category was found, and thus established threshold levels as illustrated in Table 3 and Fig. 2.

The established threshold SRH response levels according to the aggregate distribution of SHARE respondents' health index were then used to re-classify individuals in ordinal categories, in order to maintain global European SRH frequencies (as in Table 3). Global response frequencies are maintained, but because of psychological, socio-economic and response heterogeneity control, an individual which initially perceived herself as being in a poor state of health may very well end up classified as in a good state (after, for instance, her pessimism and educational level is controlled for). These values were then age-sex standardized (i.e., the weights of each self-response category in each country were recalculated as if all countries had the same age-sex distribution) and the results obtained by country were then ranked as presented in Fig. 3 .

Table 3 Computing health index quantiles to establish threshold levels for SRH

\begin{tabular}{llrcr}
\hline Obs & SRH & Freq. & Cumulative Freq. & Centile \\
\hline 10,859 & 1 & 8.14 & 8.14 & 0.674 \\
& 2 & 27.18 & 35.33 & 0.861 \\
& 3 & 40.84 & 76.17 & 0.955 \\
& 4 & 16.59 & 92.75 & 0.989 \\
& 5 & 7.25 & 100.00 & 1.000 \\
\hline
\end{tabular}

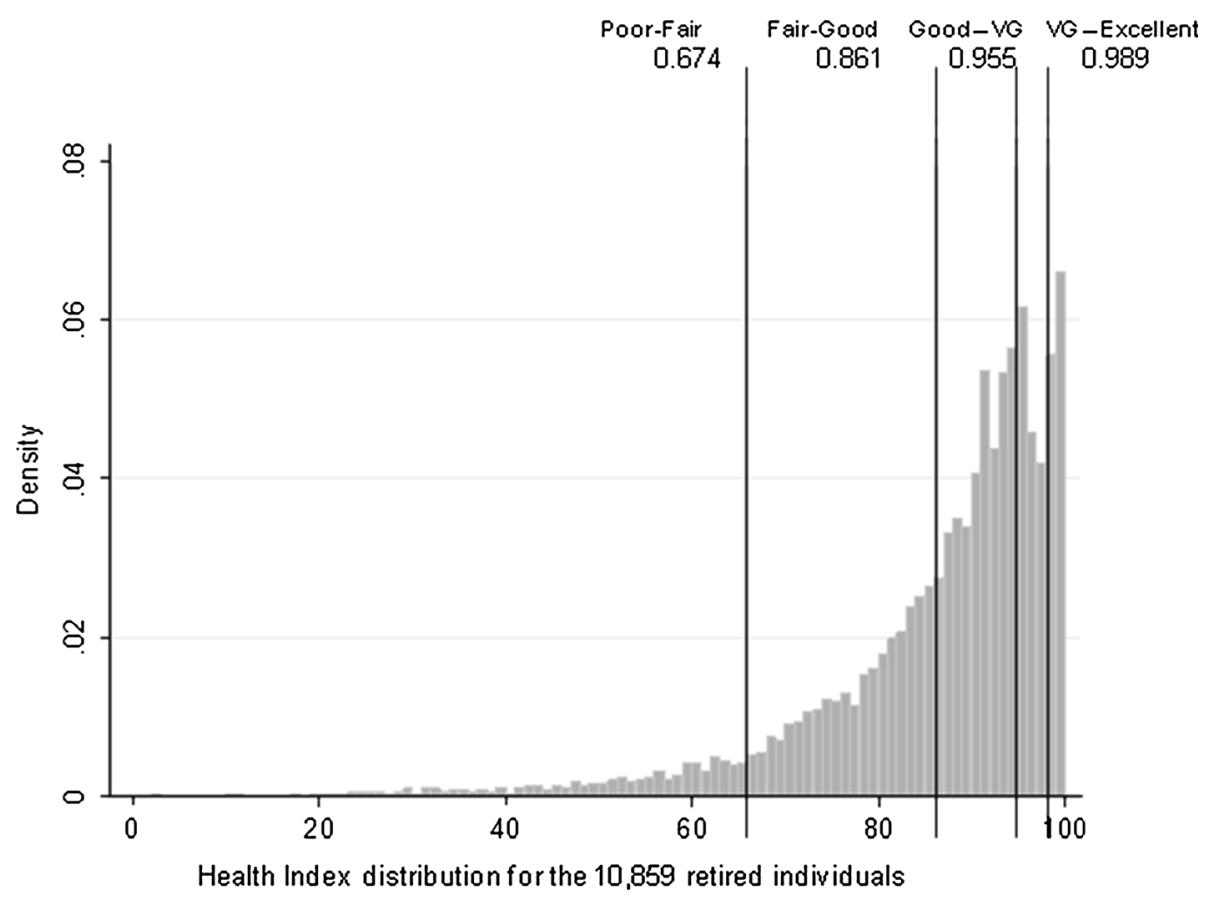

Fig. 2 Health Index distribution, and SRH thresholds 


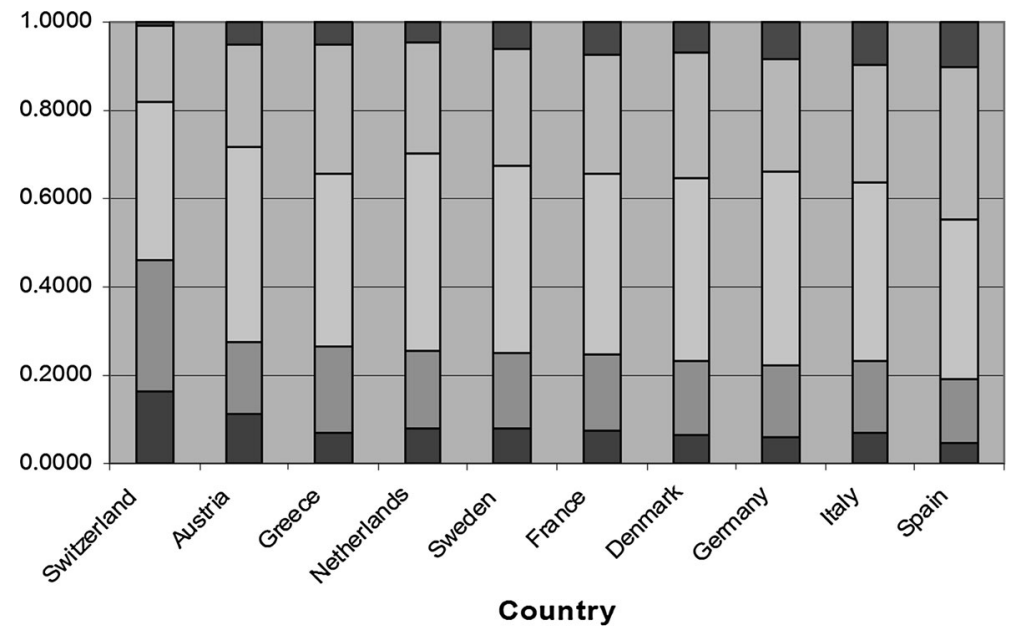

$\square$ Excelent $\square$ Very Good $\square$ Good $\square$ Fair $\square$ Poor

Fig. 3 Age-Sex Standardized Adjusted SRH by country, after heterogeneity control (using HOPIT), for the 10,859 individuals

A comparable ranking of public health of retired citizens across Europe is revealed, adjusted and cleared from reporting differences. The most obvious result is that Central European countries such as Switzerland and Austria move straight across the chart to occupy better positions, whereas these results reveal not so optimistic realities for Northern or Scandinavian countries such as Sweden and Denmark. Although Mediterranean countries maintain at the lower end, some rather drastic changes are observed, in cases such as Germany, or Greece which unveil a much better health status than the one initially revealed. Finally, a 'leveling' down of disparities is found. According to original self-rated health (as in Fig. 1), there seemed to be a much wider gap in health distribution than is actually found.

\section{Can older Europeans Be Active? Health Implications on (In)activity and Quality of Life}

\subsection{Activity}

In the context of developed countries, successful aging is multidimensional, and involves not only individuals' physical health, cognitive and psychological well-being, but also active engagement with life (Rowe and Kahn 1997). Active engagement with life involves interpersonal relations and productive activity (Rowe and Kahn 1997). An activity is productive if it creates societal value, whether or not it is reimbursed, and further promotes engagement with life when it involves interpersonal relations, i.e., emotional and social support, contact with others, exchange of information and direct assistance (Rowe and Kahn 1997). 


\subsubsection{Outcome Variables: Active Engagement with Life}

To assess active engagement with life, we considered two dimensions from the SHARE survey. Retired individuals may have opted to continue work, after retirement, or/and may be involved in some other kind of productive activity. SHARE respondents were asked to provide information on whether they engaged in this type of activities, listed in Appendix 2 , and dummy variables were created to represent the participation of a retired respondent in each of these activities. Caring for a sick or disabled adult, providing a family member with assistance, or working as a volunteer in a local church or hospital are all examples of the productive, although unpaid, activities considered (Kerzog and Morgan 1992). If the retired elderly did none of these, they were considered inactive.

\subsubsection{Covariates and Estimation Procedure}

The health index created in the previous section, free from reporting bias, is now used as a covariate to study the precise impact health may have upon older Europeans' engagement in professional or socially productive activities. The finding that socio-economic status has no particular relevance in determining the health of older Europeans is critical to the methodology chosen in this section, as it rules out and possible circularity between those variables, before proceeding with analyzing impacts physical and psychological dimensions contained in the health indicator may have on engagement in activities.

The probability of enrollment in each of these activities was thus estimated through probit regressions using gender and country dummies, net worth ${ }^{5}$ and educational level dummies. Three continuous variables were considered: income ${ }^{6}$, age and the health index. From our original 10,859 individuals, only 37 observations were lost due to missing values. Imposing a priori assumptions on linearity of continuous covariates can lead to biased estimates and the masking of some important patterns of relationships (Wood 2006; Zanin and Marra 2012; Marra and Radice 2013). In order to check for possible nonlinearities in the relationship of each of the continuous covariates with our dependant variables, we introduced all different combinations of quadratic and cubic terms ${ }^{7}$ for the three covariates in each of the regressions. Introducing quadratic terms to account for possible nonlinearities in labor participation equations is a common procedure (see, for instance, Dustmann and Meghir 2005). In most cases, we found that adding quadratic terms (particularly in the case of Income) decreased considerably the significance of each coefficient, and that it would be preferable to simply consider the linear relationship. The relevant forms of nonlinearity where identified and only these are reported in Tables 3 and 4, having registered high goodness-of-fit for all regressions presented in the later, when each engagement in each specific form of activity is estimated, rather than general participation.

\footnotetext{
5 Though SHARE contains information that would allow a computation of a value for net worth, a good portion of individuals have negative values with origin in debt. Furthermore, the degree of reliability in an absolute exact value comprehending all net worth possessed by an individual is questionable. The best option was therefore to keep using the dichotomous variables used in the previous estimation of the Health Index.

${ }^{6}$ Income was logarithmized to ease interpretation.

7 Cubic terms were all found insignificant. We also included a "pure" quadratic term, by centering the covariate (subtracting the mean from each of the observed individual value before squaring it). Combinations of linear and quadratic terms were found more significant, in the cases presented.
} 


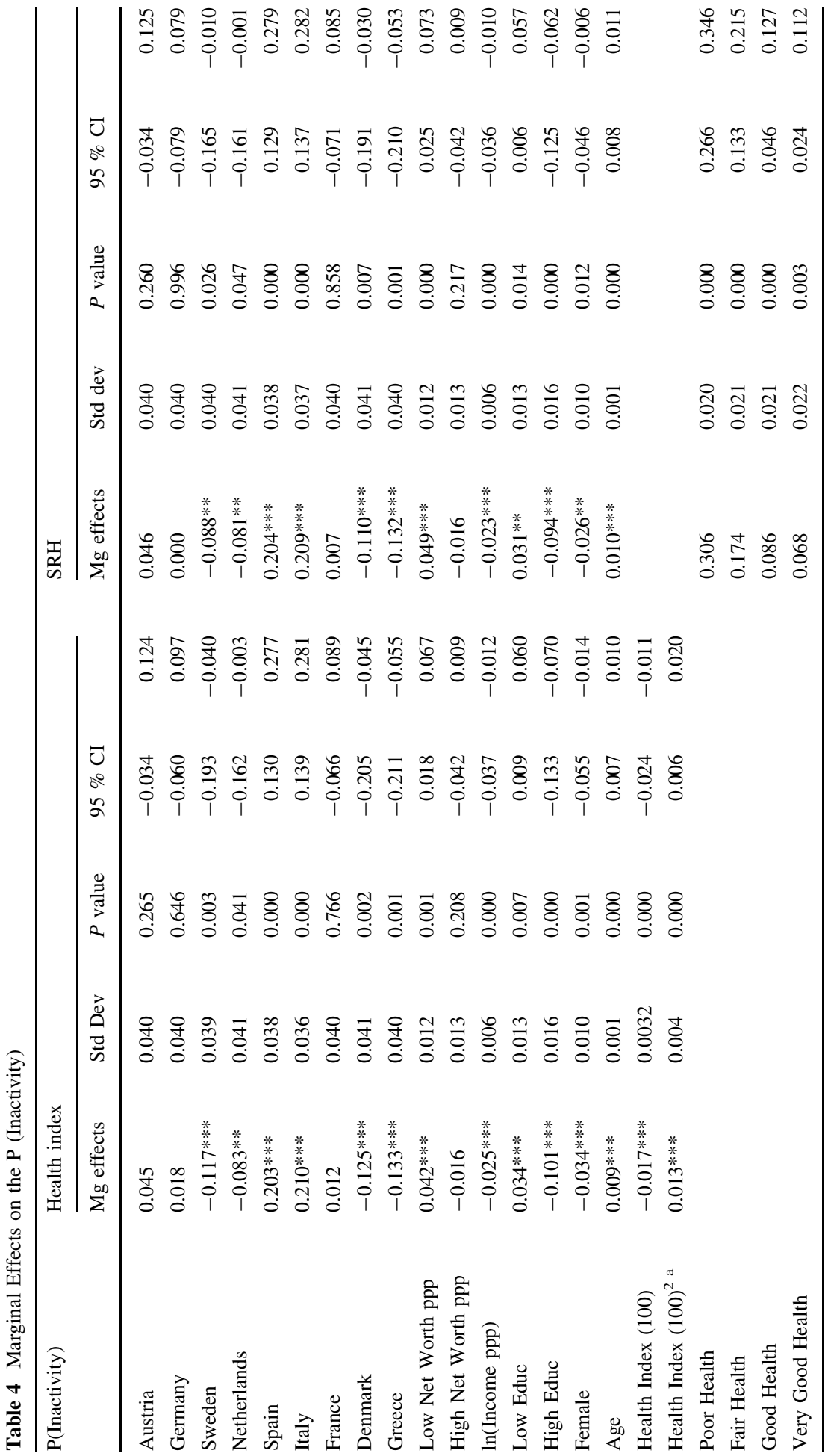




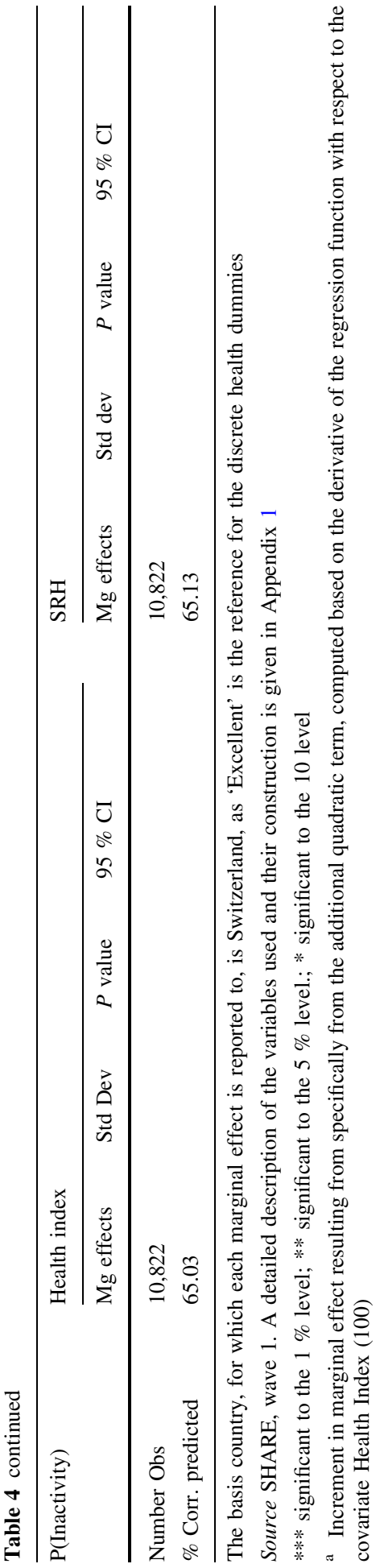




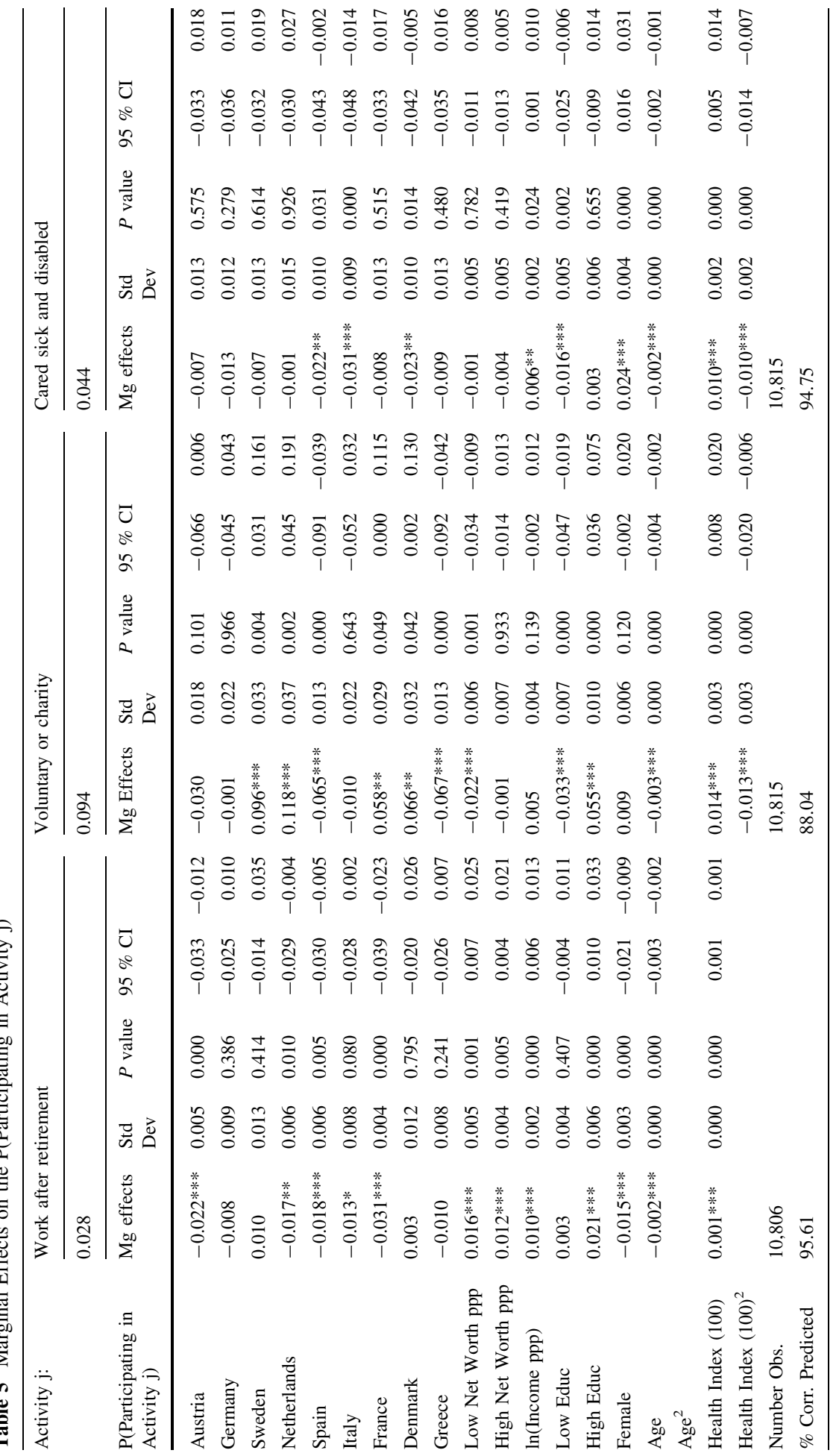




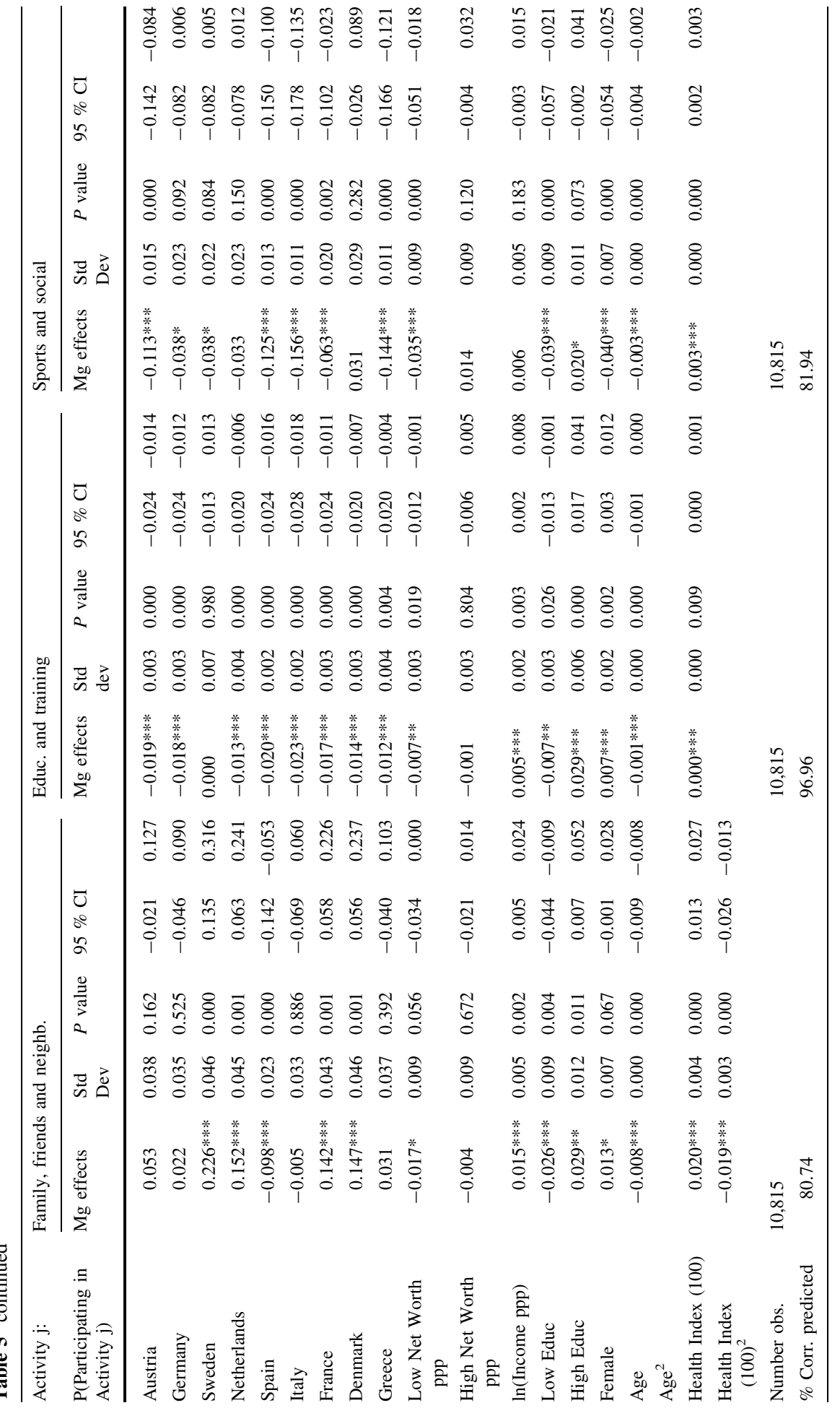




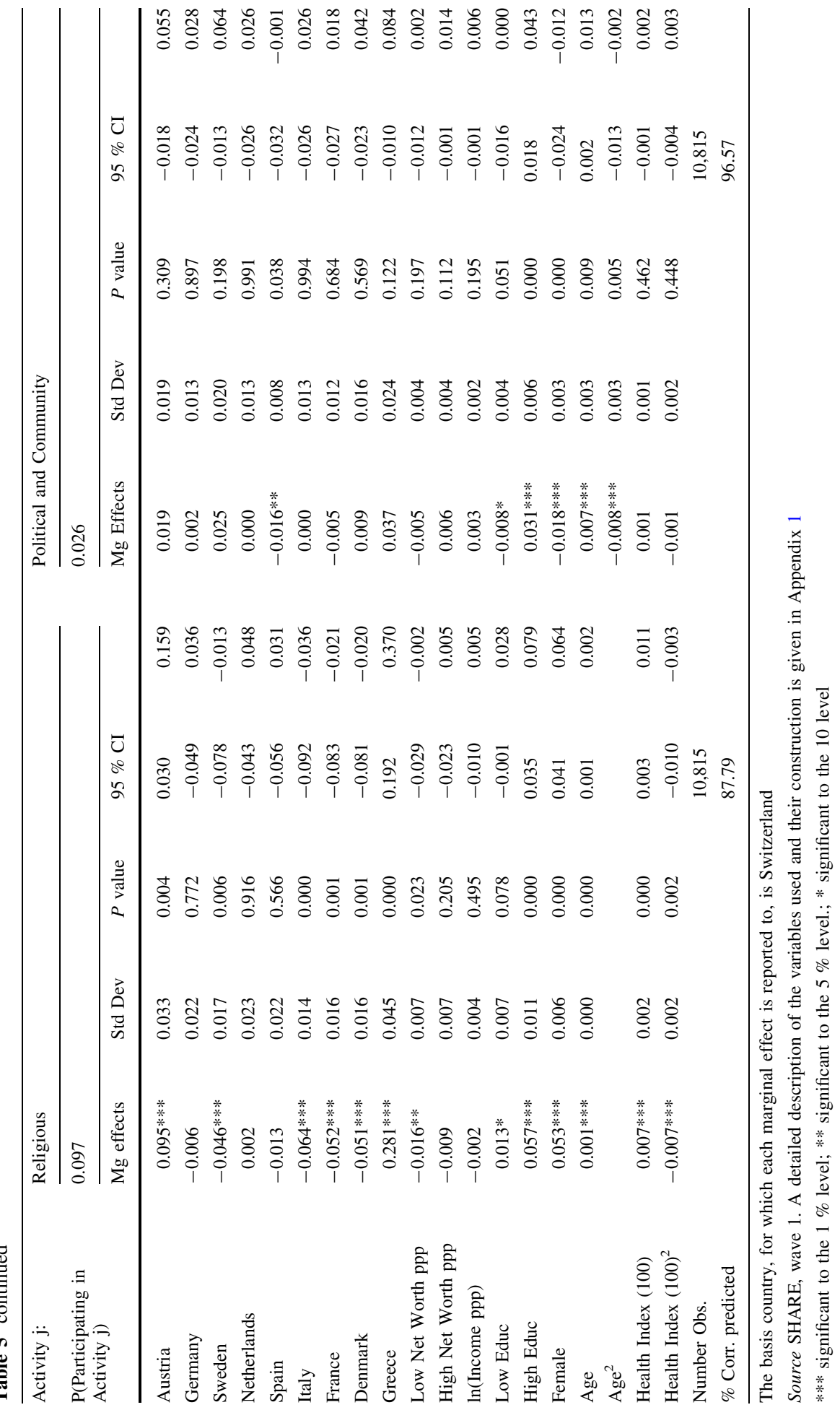


Table 6 Drop-off questionnaire and non-response subsamples

\begin{tabular}{|c|c|c|c|c|c|}
\hline & \multicolumn{2}{|c|}{ Drop-off respondants } & \multicolumn{2}{|c|}{ Non-respondants } & \multirow[t]{2}{*}{$P$-value } \\
\hline & $\begin{array}{l}\text { Mean } \\
\mathrm{n}=6,730\end{array}$ & Std. Dev & $\begin{array}{l}\text { Mean } \\
n=4,129\end{array}$ & Std. Dev & \\
\hline Low Net Worth ppp & 0.265 & 0.441 & 0.269 & 0.444 & 0.636 \\
\hline High Net Worth ppp & 0.226 & 0.416 & 0.243 & 0.434 & 0.055 \\
\hline $\ln ($ Income ppp) & 9.568 & 0.873 & 9.558 & 0.900 & 0.563 \\
\hline Low Educ & 0.548 & 0.499 & 0.572 & 0.489 & 0.011 \\
\hline High Educ & 0.152 & 0.364 & 0.137 & 0.338 & 0.034 \\
\hline Female & 0.459 & 0.498 & 0.457 & 0.498 & 0.768 \\
\hline Age & 70.173 & 9.030 & 70.625 & 9.895 & 0.017 \\
\hline Health Index (100) & 86.239 & 14.671 & 87.002 & 14.994 & 0.010 \\
\hline
\end{tabular}

a $P$ value for hypothesis test for equal means

\subsubsection{Results}

Table 4 presents the results for probit regressions on the probability of total inactivity postretirement, using the health index (recalculated to the 0-100 interval for ease of interpretation) and comparing its performance to the original self-rated health discrete measure, which is commonly used. A difference in the magnitude and shape of the health impact is estimated, taking advantage of the continuous nature of the health index as it allows for the identification of nonlinear effects on the engagement of some form of activity The role of health is evidently significant, with an average $0.4^{8}$ percentage point (p.p.) increase in the probability of participating in some form of activity in the community for each p.p. increase in the health index. This represents an average differential in the probability of participating, for someone in the poor threshold, as opposed to someone in the excellent threshold, of around 15 p.p., for the average SHARE retired respondent. ${ }^{9}$ However, this differential would be close to an overwhelmingly twofold 30 p.p. value had the original self-rated health indicators been used, without accounting for perception bias, as was done. This overestimation is easily understood by the additional information given by the quadratic term associated to the continuous measure for health on the shape of the influence health exerts. The positive increment each p.p. in health plays on the probability of participation in some form of activity is diluted as an individual position's himself higher in the health index scale.

All other common independent variables have similar estimated impacts. Men present around 3 p.p. lower participation probability rates, whilst age obviously assumes a significant role, with a decrease in participation probability of approximately 1 p.p. for each additional year of life. Countries also present significant differences in participation rates, with Mediterranean, Southern country citizens, with the exception of Greece, presenting higher probabilities of inactivity, whilst individuals from Northern and Scandinavian countries have a clearly higher propensity to engage in some kind of activity. Also

\footnotetext{
8 The total marginal effect at the mean is 0.4 p.p.. combining-1.7 p.p. associated to the health index linear term and 1.3 p.p.associated with the quadratic term. The 1.3 p.p. portion resulted from the derivative of the additive quadratic term in the regression function with respect to health index.

9 The average differential in the health index, when comparing these two types of individual health, is around 37.5 p.p.
} 
significant, is the role of Socio-Economic stratifiers, in particular education, with a 13.5 p.p. average differential, between higher and lower educated citizens, in the probability of actively participating in any kind of activity. High net worth apparently doesn't play a role in determining elderly enrollment in activities, whilst low net worth obviously contributes to inactivity.

We proceeded with estimating the impacts this set of covariates would have in each specific activity, and the results were those presented in Table 5, with very high percentage correctly predicted. The results for the positive impact of the same 37.5 differential better health as before on the probability of engaging in a certain activity were particularly significant and larger for working after retirement (3.3 p.p.), voluntary or charity work (4.5 p.p.), and performing sports and social activities (10.3 p.p.). However, they were fairy marginal in all other cases, particularly political and community activities, which seems reasonable, as they involve motivations of a different sort, concerning personal achievements, beliefs and convictions, which are not as sensitive to health disabilities. Some nonlinearities were observed in the relationship between health and participating in activities such as voluntary or charity work, caring for the sick or disabled, family, friends or neighbors, religious or political activities. The positive increment each p.p. in health plays on the probability of participation in any of these activities is diluted as an individual position's himself higher in the health index scale. A similar decreasing effect was also found for the negative role age plays on political or community activities. Other than this, age was found to have a linear effect on elderly citizens probability of engagement in activities.

It is also noticeable the fact that individuals from higher socio-economic backgrounds present higher probabilities of enrolling in activities post-retirement.

\subsection{Quality of Life}

\subsubsection{Outcome Variable: Poor Quality of Life}

As to quality of life, it is distinct from standard of living, and thus rather than addressing it through the mere measurement of socio-economic indicators, life-styles or any material dimension of it, it was evaluated through a socio-psychological approach, and then we analyzed how this individual state-of-mind or well-being could be affected by socioeconomic, health and other individual characteristics. Quality of life in older age is thus regarded here as the degree to which human needs are satisfied, which in this stage of the life course translates itself into four domains of need which seem to be particularly relevant: control, autonomy, self-realization, and pleasure (following Knesbeck et al. 2005; Patrick et al. 1993; Turner 1995; Doyal and Gough 1991). Control is interpreted as the ability to actively intervene in one's environment (Patrick et al. 1993). Autonomy is defined as the right of an individual to be free from the unwelcome interference of others (Patrick et al. 1993). Self-realization and pleasure mean to capture the active and reflexive processes of being human (Turner 1995). Following Doyal and Gough 1991 and Knesbeck et al. 2005, the CASP-12 was used, treating these four domains as equal rather than hierarchically organized. The CASP-12 correlated highly with the Life Satisfaction Index (Knesbeck et al. 2005), a measure commonly used in the studies of positive aging and of concurrent validity (Blane et al. 1999). The dummy 'poor quality of life' was created considering individuals with a CASP-12 below the 35-point threshold, following Knesbeck et al. (2005). Around $37 \%$ of the individuals reported a poor quality of life. 


\subsubsection{Sample and Estimation Procedure}

Because information on well-being and the CASP-12 is based on the SHARE drop-off questionnaire, the sample size in the case of elderly retired citizens reduced to an observed return rate of around two-thirds of the original sample, which still seems fairly significant for a study of such a matter. This raises, however, the issue of sample self-selection. When the interest is in quantifying the relationship between various demographic and socioeconomic characteristics and an elderly well-being outcome variable in the population of retired citizens, such as quality of life measured by CASP-12, then using the responding subsample is likely to produce biased estimates if and only if the outcome of interest is observed for a restricted non-randomly selected sample of the population (Marra and Radice 2013). In this case in particular, SHARE data was collected using a computer assisted personal interviewing (CAPI) program, including demographic, health and socioeconomic observables (which are in this case the covariates of interest) for all the previously analyzed sample of 10,859 respondents, supplemented by a self-completion questionnaire, which was entirely completed and returned by 6,730 individuals. The descriptive statistics for the respondent and non-respondent subgroups are presented in Table 6. Average respondent characteristics in both subgroups are found to be statistically similar to the $1 \%$ significance level in all cases, therefore presenting no reason for suspecting sample selection.

\subsubsection{Results}

Table 7 presents the results obtained for the influences of the considered set of regressors on the probability of an individual regarding himself as having a poor quality of life, again considering the traditional SRH measure and the generated indicator from Sect. 2. The results were that the average differential of 37.5 percentage points (p.p.) in the health indicator (between the average poor and excellent health SHARE retired respondent) would represent an approximate 56 p.p. differential in probability of having a poor quality of life. ${ }^{10}$ Again, the results for the effect of health are milder than those obtained had the SRH been used (59.4 p.p. probability differential), without previously accounting for reporting heterogeneity bias.

Health, age, absolute income and high levels of education were all found to be largely significant, contrasting, for instance, to gender. Whilst gender plays an important role in elderly Europeans' enrollment in activities it is not relevant in determining quality of life. Each additional year of life seems to significantly increase the probability of registering poor quality of life by 0.6 p.p., though it would have been estimated in 0.8 p.p. had the $\mathrm{SRH}$ been used to capture health. Low educational levels prove largely insignificant, whilst highly educated cohorts have a significantly lower probability of registering poor quality of life by 9.5 p.p. For elderly Europeans high net worth has a low significance impact in quality of life, whereas belonging to a low net worth group has a significant 5.3 p.p. effect on the probability of having poorer quality of life. On the other hand, each $1 \%$ variation in income significantly reduces the probability of poor quality of life by an average 3.3 p.p.

Nonlinearities were checked for in the poor quality of life relationship with income, as well as age and health, but effects were found to be significant when considered in the linear form, thus not depending on the observed level.

${ }^{10}$ If the marginal effect were to maintain across all the domain of the variables. 


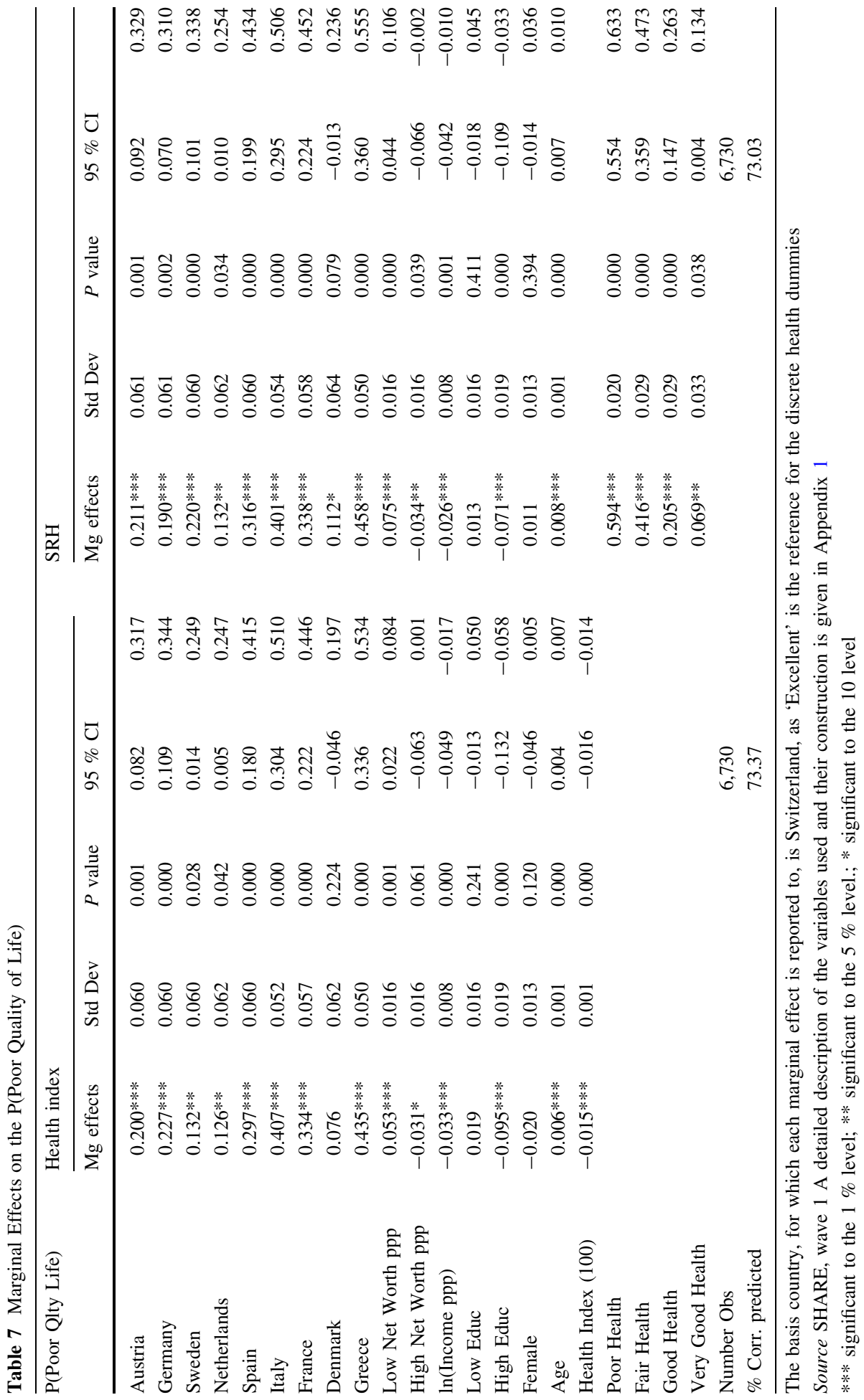




\section{Conclusions}

This paper presents an empirical strategy and conceptual framework which allows us to assess individual state of health of retirees across a diversity of socio-economic backgrounds, psycho-cognitive behavior, and multi-cultural perspectives, by controlling for individual heterogeneity in self-rated health responses. This allowed not only the characterization of retired citizens' health across ten different European countries, but also to estimate a weight (or disabilities) associated to each type of health determinants, whether derived from endowment, access or individual choices. Somewhat different results are from those initially revealed by SHARE respondents, not only in terms of different individual health status' (from those reported), but also to the aggregate country level, with an apparent leveling down of European disparities, and a new 'ranking' emerging, quite different from the one reported.

Interestingly, and contrary to what could have been previously hypothesized based on Sen's (2004) capability approach or cumulative advantage or disadvantage theory (Dannefer 2003; Ferraro and Shippee 2009), evidence is found that in a developed economy contexts, access, or socio-economic determinants are not significant in explaining individual health. They act rather at the perceptive level influencing self-reports of health (which is consistent with Sen's view (2002)), together with other psycho-cognitive dimensions. Dimensions which must, crucially, be taken into account before policy design, when the measure for health is based on a self-report of an elderly retired population, as it so commonly is. The evidence found does however corroborate what was previously hypothesized: physical endowment, disabilities or psychological dimensions of well-being (Rowe and Kahn 1997) are determinant in explaining health outcomes for developed economies, amongst a population unaccustomed to adverse conditions, and more important than access variables. The finding that socio-economic determinants are not found to be influential enforces the idea that health provision systems for the elderly in Europe are fairly general, and equalitarian, even across countries. The implications for public policy are very significant. This means that health inequalities in Europe (a different case may occur for well-being) do not have an origin on socio-economic inequalities, nor necessarily on country-specific effects. Rather health inequalities across European nations depend on the incidence of disease (physical and mental) and behavioral causes (e.g., smoking, playing sports etc.). This and the disability weights reported in Table 2, provides a clear hint for policymakers when establishing policy strategy and priorities.

A second part of this paper was devoted to the topic of positive aging in developed economies (particularly under Rowe and Kahn's perspective (1997)), and finding how health co-exists with other determinants of active participation and social engagement to life or even quality of life, and what are the policy implications of this.

As to influences on (in)activity and quality of life of retired Europeans, contrary to what has been found in developing contexts (Hsu 2009), there is no doubt the health indicator (and the physical disabilities that weigh considerably on it) plays a predominant role. The consideration of nonlinearities revealed that the role health plays on the probability of participation in some form of activity is significant but, however, is diluted as an individual position's him or herself higher in the health index scale. This represents obvious implications in terms of optimum investments in health promotion projects, which results indicate may play an obvious role in improving active citizenship, with higher returns to scale when targeted at earlier old age citizens. It also hints at a rout for delaying age-related declines, particularly when considering the paper's results on the importance of health in determining quality of life, which in turn is found to declining with age, somewhat 
consistent with recent findings in developed countries such as Germany (Fujita and Diener 2005) or Sweden (Berg et al. 2009).

As to gender differences, concerning elderly well-being the literature diverges in the nature of the difference. Self-rated health had been found related to life satisfaction, but only in women (Berg et al. 2006), with older women having found to have lower subjective well-being than men (Pinquart and Sörensen 2001, Carmel and Bernstein 2003). Others have found that the relationship between life satisfaction and the quality of social relationships (Li and Liang 2007, Röcke and Lachman 2008)—captured by CASP-12 questions-is stronger in women than men (Cheng and Chan 2006). Gender differences could thus be expected, given that women are found in this study to be more likely involved in most of the work-related and social activities considered (curiously with the exception of voluntary or charity work). This more so because work and retirement patterns have been found to be related to life satisfaction in developed economies (Germany, for instance, in Pinquart and Schindler 2007). However this was not the case. We therefore find a different result for elderly Europeans than Cheng and Chan (2006) did across a sample of 1,616 Chinese individuals in Hong-Kong, aged above 60, possibly resulting from cultural and economic development differences. In sum, whilst gender plays an important role in elderly Europeans' enrollment in activities, it is found irrelevant in determining quality of life. Other studies have corroborated the absence of a gender difference in life satisfaction in a developed economy (Berg et al. 2006).

This paper sought to evaluate the contributions of bio-psycho-social influences on health and some of the implications for positive aging and active engagement with life (Rowe and Kahn 1997) of elderly well-being, which have been discussed. Nonetheless it aimed at comparing the relevance of these dimensions with other strands of literature that believe demographics (e.g. age and gender) or socioeconomic influences are determinant. The relative insignificance of absolute economic status to explain well-being has been reported (Tao and Chiu 2009) particularly in higher income developing countries, and when a flow of income is considered rather than a stock of wealth (Howell and Howell 2008). Whereas for elderly Europeans we find high net worth has a low significance impact in quality of life, belonging to a low net worth group has a significant effect on the probability of having poorer quality of life. This is reasonable even in more developed economies, if it is considered that it might reflect economic deprivation effects on life satisfaction (Revicki and Mitchell 1990). However, absolute income is found to significantly reduce the probability of poor quality of life. This is consistent with studies that found socioeconomic status to be related to life satisfaction in developed economies, even though only in elderly men, not women (Berg et al. 2006) and particularly when considering relative income (Ball and Chernova 2008; Easterlin and Plagnol 2008). In this European case it is irrespective of gender and relativeness. Nonlinearities were checked for in the poor quality of life relationship with income, as well as age and health, but effects were only found to be significant when considered in the linear form, thus not depending on the observed level.

Finally, what is noticeable is the fact that individuals from higher socio-economic backgrounds present higher probabilities of enrolling in activities post-retirement and having an active engagement to life. The influences in the probability of working after retirement had a particularity, in that only high educational levels have a positive influence, with low education being insignificant. This propensity to activity is consistent with current literature's findings that higher education, for instance, in later stages in life, increases the likelihood of participating in the labor force (Hirao 2001). This provides an important framework for policy-makers troubled with possible lower production and fiscal revenue 
levels from an aging population, 'weighing' on the social budget. Whilst lower levels of education don't prevent labor force participation post-retirement, an investment in the education of future generations might certainly yield economically productive (besides socially productive) retired citizens. Furthermore, concerning well-being, low educational levels prove largely insignificant, whilst highly educated cohorts have a significantly lower probability of registering poor quality of life. These results are consistent with Hsu's (2010) findings in Taiwan, which somehow rule out cumulative disadvantage theory, but rather reinforce the existence of a cumulative advantage, even in a context of more developed economies.

The results from this paper set out the path for policymakers in Europe: the literature documents positive aging and elderly well-being strongly depend on the stimulus from active engagement in socially productive activities. This paper finds both might depend on certain economic factors, even in a developed economic cross-national reality. In this context, current health care and educational policy might provide the essential and promote shrinking disparities in the lower end of the distributions, thus preventing cumulative disadvantage, which we do not find, in an older age. However, strong evidence is found that currently active engagement and quality of life most certainly are a prerogative of the more educated and the healthier retirees. This leads us to conclude on the high influence of cumulative advantage on the positive aging of Europeans. An advantage that must be leveraged by education and health policy makers. This paper thus hints a route for policy makers to take, in contouring an aging and possibly (un)productive European population, transforming what could be a "social burden" into an asset.

Acknowledgments A first version of this paper was funded by Fundação para a Ciência e Tecnologia (FCT), through a PhD scholarship with reference SFRH/BD/23669/2005, financed by POPH-QREN and also by the European Social Fund and national funds from the Ministério da Ciência, Tecnologia e Ensino Superior (MCTES). A working paper version of this paper was accepted at the 3rd Advanced Summer School in Economics and Econometrics, August 2008, with Distinguished Guest Professor William H. Greene lecturing on the topic of 'Discrete Choice Modeling'. The authors are very grateful to him for his comments and all the constant support which he has given since then.

\section{Appendix 1: Definition of variables}

$\mathrm{Ph}$ —Physical Health; Chronic Disabilities and Functioning Limitations

\begin{tabular}{ll}
\hline Disability & Description \\
\hline Heart attack or other heart problems & Circulatory \\
High blood pressure & Circulatory \\
High blood cholesterol & Circulatory \\
Stroke or cerebral vascular disease & Digestive/ulcers; Genitourinary \\
Diabetes & Endocrine \\
Chronic lung disease & Musculoskeletal \\
Asthma & Musculoskeletal \\
Arthritis & Musculoskeletal \\
Osteoporosis & Neoplasms \\
Cancer or Malignant Tumor & Nervous System \\
Stomach, duodenal or peptic ulcer & Nervous system \\
\hline
\end{tabular}




\begin{tabular}{ll}
\hline Disability & Description \\
\hline Parkinson disease & Poor Vision \\
Cataracts & Respiratory \\
Hip fracture or femoral & Respiratory \\
Other conditions & Other chr. Cond. \\
Low Grip Strength $^{(a)}$ & $<$ Bottom tertile \\
No Grip Strength & (a) \\
Low Walk. Speed $^{(b)}$ & Test not completed \\
Poor Mobility $^{(c)}$ & $<0.4$ m/s \\
ADL $^{(d)}$ & more than 2 \\
IADL $^{(e)}$ & 1 or more
\end{tabular}

(a) Binary variable indicating that from 4 measurements ( 2 in each hand) with a dynamometer, the largest is below the bottom tertile, in the case of "low grip strength" or the individual wasn't able to complete the test ("no grip strength"). Hand grip strength in middle age has been shown to be predictive of the incidence of functional limitations, disability and even mortality in old age (Frederiksen et al. 2002; Rantanen et al. 1998)

(b) It is measured by a timed walk over a short distance $(2.5 \mathrm{~m})$. Two measurements were made, of which we take the fastest. A walking speed of $0.4 \mathrm{~m} / \mathrm{s}$ or slower is used as the cut-off point for 'low walking-speed' (Steele et al. 2003). Unsuccessful attempts-independent of the reason-are also coded as having low walking speed. Respondents younger than 75 who were not eligible for the test are coded as having a normal walking speed

(c) This variable re-categorizes the categorical variable 'mobility' into the following values: (0) Less than three limitations \& (1) three or more limitations with mobility, arm function \& fine motor function

(d), (e) ADL (activities of daily living) comprises information on limitations individuals have with daily activities, i.e., dressing, getting in/out of bed, bathing/showering, using the toilet and eating. IADL (Instrumental activities of daily living) comprises data on limitations with activities such as preparing a meal, shopping, taking medication, making telephone calls, doing housework, or managing money; the binary variables created and used reclassify the variable 'ADL' (or 'IADL') into two categories: (0) no ADL/IADL limitations and (1) one or more limitations with ADL/IADL

MhSP_-Mental Health and Self-Perception; Depression, Personality Traits, Cognitive Functioning

All of the following where included in vector $\mathrm{Z}$, of regressors over the thresholds:

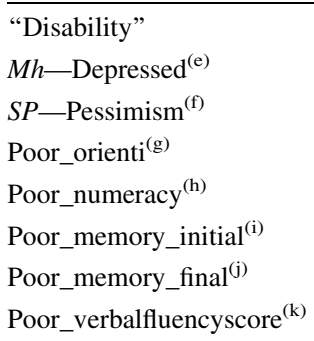


Poor_srwritingskills ${ }^{(1)}$

Poor_srreadingskills ${ }^{(\mathrm{m})}$

(e) Depression was measured using the Euro-D scale, which has been validated in an earlier cross-European study of depression prevalence, EURODEP (Prince et al. 1999a, b). For the purposes of this contribution we defined a binary variable indicating clinically significant depression as a EURO-D score greater than 3 . This cut-point had been validated in the EURODEP study, across the continent, against a variety of clinically relevant indicators. Those scoring above this level would be likely to be diagnosed as suffering from a depressive disorder, for which therapeutic intervention would be indicated. Major depression is forecast by 2020 to have risen from the fourth to the second most burdensome health condition world-wide, taking into account both associated disability and premature mortality (Murray and Lopez 1997). Late-life depression, when defined according to the broad criterion of clinical significance, is a common disorder affecting $10-15 \%$ of the over 65 year old population (Beekman et al. 1999)

(f) Dummy indicating whether an individual is a pessimist. Based on Dewey and Prince's (2005) works on SHARE module from the main questionnaire (CAPI). A high level of optimism is typically an indicator of well-being, e.g., psychological functioning, effective coping with stress, psychological well-being and physical health. Pessimism, on the other hand, has been found to be linked to learned helplessness, apathy and depressions (Ek et al. 2004)

(g)-(m) Cognitive functioning

Cognition can be divided into different domains of ability, which can be tested separately; the most important of these are orientation, memory, executive function (planning, sequencing) and language. In SHARE, cognitive ability has been measured using simple tests of orientation, memory (registration and recall of a list of ten words), verbal fluency (a test of executive function) and numeracy (arithmetical calculations). Respondents were also asked to rate subjectively their reading and writing skills

Cognitive test scores (based on Dewey and Prince 2005) used

(g) Based on orientation to time (to date, month, year and day of week) score, ranging from 0 (bad) to 4 (good). Dummy representing poor orientation if one or more errors where made (orientation score $\leq 3$ )

(h) Based on numeracy score from 1 to 5 . Dummy representing poor numeracy if score is less than 4

(i) Based on Cerad memory recall test, a word list memory test from the Consortium to establish a registry for Alzheimer's disease (CERAD) neuropsychological battery (Morris et al. 1989). Score ranges from 0 to 10. This dummy represents poor memory recall if score is less or equal to 4

(j) Similar to ${ }^{(j)}$, only taken at the end of the interview

(k) Based on the number of animals listed per minute. Considered poor if less or equal to 18

(1) Rated on a scale from 1(poor) to 5(excellent). Dummy indicating poor writing skills if rated as poor (1)

(m) Rated on a scale from 1(poor) to 5(excellent). Dummy indicating poor reading skills if rated as poor (1)

Bh-Behavioral Risks/Lifestyle Choices

\begin{tabular}{ll}
\hline Disability & Description \\
\hline Underweight & BMI $<20$ \\
Overweight & $25<$ BMI $<30$ \\
Obese & BMI $>30$ \\
Current smoker & \\
Former smoker & \\
\hline
\end{tabular}




\begin{tabular}{ll}
\hline Disability & Description \\
\hline Alcohol & More 2 glasses/day or $5 / 6$ days/week \\
Physical inactive & Neither moderate nor vigorous activity
\end{tabular}

BMI (Body Mass Index = weight in $\mathrm{kg} / \mathrm{squared}$ height in meters) was created and coded in four categories: $<20$ (underweight), 20-25 (normal weight), 25-30 (overweight), and more than 30 (obese)

\section{$\mathrm{Se}-$ Socio-Economic Characteristics}

Low Income ppp

High Income ppp

Low net-worth ppp

High net-worth ppp

Low Educ

High Educ
Below 1st quartile

Above 3rd quartile

Below 1st quartile

Above 3rd quartile

ISCED-97 classif

ISCED-97 classif

Dummy variables were calculated based on the distribution for the whole (retired and non-retired) sample of 22,600 individuals

Income and Net Worth were calculated per capita, according to household information, and using the OECD-modified equivalence scale, which assigns a value of 1 to the household head, of 0.5 to each additional adult member and of 0.3 to each child. Furthermore, these variables include some imputed values, where imputations were performed by the SHARE panel of researchers. All values were converted to Euros and purchasing parity adjusted

Education embodies human capital, which is an important determinant of health care utilization, besides acting as a good proxy for knowledge of means to deal (and prevent) health problems

The educational level was based on self-reported highest level of education, and reclassified using the UNESCO International classification of education (ISCED-97) (Organization for Economic Cooperation and Development 1999). The ISCED-97 classification scheme has 7 different levels (0-6), ranging from preprimary level of education (e.g. kindergarten) to the second stage of tertiary education (Ph.D.). The original ISCED were recoded into three broader education levels: "low" (pre-primary to lower secondary education; ISCED 0-2), "medium" (upper secondary and post-secondary, non-tertiary education; ISCED 3 and 4), and "high" (first and second stage of tertiary education; ISCED 5 and 6)

C-country dummies

\section{Appendix 2: Possible activity enrollment}

1. Done voluntary or charity work

2. Cared for a sick or disabled adult

3. Provided help to family, friends or neighbors

4. Attended an educational or training course

5. Gone to a sport, social or other kind of club

6. Taken part in a religious organisation (church, synagogue, mosque etc.)

7. Taken part in a political or community-related organisation

8. None 


\section{References}

Aspinwall, L. G., \& Taylor, S. E. (1992). Modeling cognitive adaptation: A longitudinal investigation of the impact of individual differences and coping on college adjustment and performance. Journal of Personality and Social Psychology, 63, 989-1003.

Ball, R., \& Chernova, K. (2008). Absolute income, relative income, and happiness. Social Indicators Research, 88, 497-529.

Beekman, A. T. F., Copeland, J. R. M., \& Prince, M. J. (1999). Review of community prevalence of depression in later life. British Journal of Psychiatry, 174, 307-311.

Berg, A. I., Hassing, L. B., McClearn, G. E., \& Johansson, B. (2006). What matters for life satisfaction in the oldest-old? Aging and Mental Health, 10(3), 257-264.

Berg, A. I., Hoffman, L., Hassing, L. B., McClearn, G. E., \& Johansson, B. (2009). What matters, and what matters most, for change in life satisfaction in the oldest-old? A study over 6 years among individuals 80+. Aging and Mental Health, 13(2), 191-201.

Blane, D. B., Berney, L. R., Smith, G. D., Gunnel, D. J., \& Holland, P. (1999). Reconstructing the lifecourse; health during early old age in a follow up study based on the Boyd Orr Cohort. Public Health, 113, 117-124.

Borg, C., Hallberg, I. R., \& Blomqvist, K. (2006). Life satisfaction among older elderly (65?) with reduced self-care capacity: The relationship to social, health and financial aspects. Journal of Clinical Nursing, 15, 607-618.

Borsch-Supan, A., Brugiavini, A., Jurges, H., Mackenbach, J., Siegrist, J., \& Weber, G. (Eds.). (2005). Health, Ageing and Retirement in Europe: First Results from the Survey of Health, Ageing and Retirement in Europe. MEA: Mannheim.

Borsch-Supan, A., \& Jurges, H. (Eds.). (2005). The Survey of Health, Ageing and Retirement in Europe: Methodology. MEA: Mannheim.

Brugiavini, A., Croda, E., Paccagnella, O., Rainato, R., \& Weber, G. (2005). Chapter 10 in The Survey of Health, Aging, and Retirement in Europe: Methodology. MEA: Mannheim.

Carmel, S., \& Bernstein, J. H. (2003). Gender differences in physical health and psychosocial well-being among four age-groups of elderly people in Israel. International Journal of Aging and Human Development, 56(2), 113-131.

Cheng, S. T., \& Chan, A. C. (2006). Relationship with others and life satisfaction in later life: Do gender and widowhood make a difference? The Journals of Gerontology Series B: Psychological Sciences and Social Sciences, 61(1), P46-P53.

Chou, K.-L., \& Chi, I. (2002). Financial strain and life satisfaction in Hong Kong elderly Chiense: Moderating effect of life management strategies including selection, optimization, and compensation. Aging \& Mental Health, 6(2), 172-177.

Christelis, D., Jappelli, T., \& Padula, M. (2005). Chapter 11 in The Survey of Health, Aging, and Retirement in Europe: Methodology. Mannheim: MEA.

Crossley, T., \& Kennedy, S. (2002). The reliability of self-assessed health status. Journal of Health Economics, 21, 643-658.

Dannefer, D. (2003). Cumulative advantage/disadvantage and the life course: Cross-fertilizing age and social science theory. The Journals of Gerontology Series B: Psychological Sciences and Social Sciences, 58(6), S327-S337.

Dewey, M.E. \& Prince, M.J. (2005). Chapter 3.4 and 3.5. In Borsch-Supan A, Brugiavini A, Jurges H, Mackenbach J, Siegrist J, Weber G (eds). (2005). Health, Ageing and Retirement in Europe: First Results from the Survey of Health, Ageing and Retirement in Europe. MEA: Mannheim.

Doyal, L., \& Gough, I. (1991). A theory of human need. Hong Kong: Macmillan.

Dustmann, C., \& Meghir, C. (2005). Wages, experience and seniority. The Review of Economic Studies, 72(1), 77-108.

Easterlin, R. A., \& Plagnol, A. C. (2008). Life satisfaction and economic conditions in East and West Germany pre-and post-unification. Journal of Economic Behavior \& Organization, 68(3), 433-444.

Ek, E., Remes, J., \& Sovio, U. (2004). Social and developmental predictors of optimism from infancy to early adulthood. Social Indicators Research, 69(2), 219-242.

Ferraro, K. F., \& Shippee, T. P. (2009). Aging and cumulative inequality: How does inequality get under the skin? The Gerontologist, 49(3), 333-343.

Frederiksen, H., Gaist, D., Petersen, H. C., Hjelmborg, J., McGue, M., Vaupel, J. W., et al. (2002). Hand grip strength: a phenotype suitable for identifying genetic variants affecting mid- and late-life physical functioning. Genetic Epidemiology, 23, 110-122. 
Fujita, F., \& Diener, E. (2005). Life satisfaction set point: stability and change. Journal of Personality and Social Psychology, 88(1), 158.

Graham, J. W. (2009). Missing data analysis: Making it work in the real world. Annual Review of Psychology, 60, 549-576.

Greene, W., \& Hensher, D. (2010). Modeling ordered choices: A primer and recent developments. Cambridge: Cambridge University Press.

Groot, W. (2000). Adaption and scale of reference bias in self-assessments of quality of life. Journal of Health Economics, 19, 403-420.

Hirao, K. (2001). The effect of higher education on the rate of labor-force exit for married Japanese women. International Journal of Comparative Sociology, 42(5), 413-433.

Howell, R. T., \& Howell, C. J. (2008). The relation of economic status to subjective well-being in developing countries: A meta-analysis. Psychological Bulletin, 134(4), 536-560.

Hsu, H. C. (2009). Physical function trajectories, depressive symptoms, and life satisfaction among the elderly in Taiwan. Aging \& Mental Health, 13(2), 202-212.

Hsu, H. C. (2010). Trajectory of life satisfaction and its relationship with subjective economic status and successful aging. Social Indicators Research, 99(3), 455-468.

Human Mortality Database (2002). At www.mortality.org. Accessed 5 May, 2010.

Jurges, H. (2007). True health vs response styles: Exploring cross-country differences in self-reported health. Health Economics, 16, 163-178.

Jurges, H., Avendano, M., \& Mackenback, J. (Eds.). (2007). How comparable are different measures of selfrated health? Evidence from five European countries. Mannheim: MEA.

Kerkhofs, M., \& Lindeboom, M. (1995). Subjective health measures and state dependent reporting errors. Health Economics, 4, 221-235.

Kerzog, A. R., \& Morgan, J. N. (1992). Age and gender differences in the value of productive activities: Four different approaches. Research on Aging, 14, 169-198.

King, G., Murray, C. J., Salomon, J. A., \& Tandon, A. (2004). Enhancing the validity and cross-cultural comparability of measurement in survey research. American Political Science Review, 98, 191-207.

Knesebeck, O., Hyde, M., Higgs, P., Kupfer, A. \& Siegrist, J. (2005). Chapter 4.6. In Borsch-Supan A, Brugiavini A, Jurges H, Mackenbach J, Siegrist J, Weber G (eds). (2005). Health, Ageing and Retirement in Europe: First Results from the Survey of Health, Ageing and Retirement in Europe. MEA: Mannheim.

Li, Y., Aranda, M. P., \& Chi, I. (2007). Health and life satisfaction of ethnic minority older adults in mainland China: Effects of financial strain. International Journal of Aging and Human Development, 64(4), 361-379.

Li, L. W., \& Liang, J. (2007). Social exchange and subjective well-being among older Chiense: Does age make a difference? Psychology and Aging, 22(2), 386-391.

Lindeboom, M., \& Van Doorslaer, E. (2004). Cut-point shift and index shift in self-reported health. Journal of Health Economics, 23, 1083-1099.

Marra, G., \& Radice, R. (2013). A penalized likelihood estimation approach to semiparametric sample selection binary response modeling. Electronic Journal of Statistics, 7, 1432-1455.

Morris, J. C., Heyman, A., Mohs, R. C., \& Hughes, J. P. (1989). The consortium to establish a registry for Alzheimer's disease (CERAD): I. Clinical and neuropsychological assessment of Alzheimer's disease. Neurology.

Murray, C. J. L., \& Lopez, A. D. (1997). Global mortality, disability, and the contribution of risk factors: Global Burden of Disease Study. Lancet, 349, 1436-1442.

Patrick, B. C., Skinner, E. U., \& Connell, J. P. (1993). What motivates children's behaviour and emotion in the academic domain? Journal of Personality and Social Psychology, 65, 781-791.

Pinquart, M., \& Schindler, I. (2007). Changes of life satisfaction in the transition to retirement: a latent-class approach. Psychology and Aging, 22(3), 442.

Pinquart, M., \& Sörensen, S. (2001). Gender differences in self-concept and psychological well-being in old age: A meta-analysis. Journal of Gerontology Series B, Psychological Sciences and Social Sciences, 56B(4), P195-P213.

Prince, M. J., Reischies, F., Beekman, A. T. F., Fuhrer, R., Jonker, C., \& Kivelä, S. L. (1999a). Depression symptoms in late life assessed using the EURO-D scale. British Journal of Psychiatry, 174, 339-345.

Prince, M. J., Reischies, F., Beekman, A. T. F., Fuhrer, R., Jonker, C., Kivelä, S. L., et al. (1999b). Development of the EURO-D scale - a European Union initiative to compare symptoms of depression in 14 European centres. British Journal of Psychiatry, 174, 330-338.

Rantanen, T., Masaki, K., Foley, D., Izmirlian, G., White, L., \& Guralnik, J. M. (1998). Grip strength changes over 27 years inJapanese-American men. Journal of Applied Physiology, 85, 2047-2053. 
Rebelo, L. P. \& Pereira, N. S. (2011). Disentangling 'true' underlying health from response styles: a separate identification of direct health effects from self-categorization effects. Essay from the Faculdade de Economia do Porto Doctoral Thesis "THE ECONOMICS OF HEALTH AND HEALTH CARE: Assessing health determinants and impacts on an aging population", http://repositorio-aberto.up.pt/ bitstream/10216/62305/2/TESEFinal.pdf.

Revicki, D. A., \& Mitchell, J. P. (1990). Strain, social support, and mental health in rural elderly individuals. Journal of Gerontology, 45(6), S267-S274.

Röcke, C., \& Lachman, M. E. (2008). Perceived trajectories of life satisfaction across past, present, and future: Profiles and correlates of subjective change in young, middle-aged, and older adults. Psychology and Aging, 23(4), 833-847.

Rowe, J. W., \& Kahn, R. L. (1997). Successful aging. The Gerontologist, 37(4), 433-440.

Sen, A. (2002). Health: perception versus observation. British Medical Journal, 324, 860-861.

Sen, A. (2004). Why health equity? In S. Anand, F. Peter, \& A. Sen (Eds.), Public health, ethics, and equity. Oxford: Oxford University Press.

Siegrist, J., Wahrendorf, M., Knesebeck, O., Jurges, H., \& Borsch-Supan, A. (2006). Quality of work, wellbeing, and intended early retirement of older employees-baseline results from the SHARE Study. European Journal of Public Health, 17(1), 62-68.

Steele, N., Huppert, F. A., McWilliams, B., \& Melzer, D. (2003). Physical and cognitive function. In M. Marmot, J. Banks, R. Blundell, C. Lessof, \& J. Nazroo (Eds.), Health, Wealth and Lifestyles of the Older Population in England: The 2002 English Longitudinal Study of Ageing. London: IFS.

Tao, H. L., \& Chiu, S. Y. (2009). The effects of relative income and absolute income on happiness. Review of Development Economics, 13(1), 164-174.

Turner, B. (1995). Aging and identity some reflections on the somatisation of the self. In M. Featherstone \& A. Wernick (Eds.), Images of aging (pp. 245-260). London: Routledge.

van Doorslaer, E., \& Gerdtham, U. (2003). Does inequality in self-assessed health predict inequality in survival by income? Evidence from Swedish data. Social Science and Medicine, 57(9), 1621-1629.

van Doorslaer, E., \& Jones, A. M. (2003). Inequalities in self-reported health: validation of a new approach to measurement. Journal of Health Economics, 22, 61-87.

Weisbrod, B. (1991). The health care quadrilemma: an essay on technological change, insurance, quality of care, and cost containment. Journal of economic literature, 29(2), 523-552.

Zanin, L., \& Marra, G. (2012). A comparative study of the use of generalized additive models and generalized linear models in tourism research. International Journal of Tourism Research, 14(5), 451-468. 
Copyright of Social Indicators Research is the property of Springer Science \& Business Media B.V. and its content may not be copied or emailed to multiple sites or posted to a listserv without the copyright holder's express written permission. However, users may print, download, or email articles for individual use. 